\title{
Roles of air-sea coupling and horizontal resolution in the climate model simulation of Indian monsoon low pressure systems
}

Article

Accepted Version

Levine, R. C., Klingaman, N. P. ORCID: https://orcid.org/00000002-2927-9303, Peatman, S. and Martin, G. M. (2021) Roles of air-sea coupling and horizontal resolution in the climate model simulation of Indian monsoon low pressure systems. Climate Dynamics, 56. pp. 1203-1226. ISSN 0930-7575 doi: https://doi.org/10.1007/s00382-020-05526-6 Available at https://centaur.reading.ac.uk/93808/

It is advisable to refer to the publisher's version if you intend to cite from the work. See Guidance on citing.

To link to this article DOI: http://dx.doi.org/10.1007/s00382-020-05526-6

Publisher: Springer

All outputs in CentAUR are protected by Intellectual Property Rights law, including copyright law. Copyright and IPR is retained by the creators or other copyright holders. Terms and conditions for use of this material are defined in the End User Agreement. 


\section{CentAUR}

Central Archive at the University of Reading

Reading's research outputs online 


\title{
Roles of air-sea coupling and horizontal resolution in the climate model simulation of Indian monsoon low pressure systems
}

\author{
Richard C. Levine - Nicholas P. Klingaman • Simon C. Peatman • Gill \\ M. Martin
}

the date of receipt and acceptance should be inserted later

Received: date / Accepted: date

Abstract The roles of air-sea coupling and horizontal resolution in the representation of Indian monsoon low pressure systems (LPS) in Met Office Unified Model (MetUM) global climate simulations are investigated. To avoid the generally large sea surface temperature (SST) biases in standard coupled atmosphere-ocean global climate models (GCMs), the analysis is performed on experiments from an atmosphere model coupled to a mixed-layer ocean model (MetUM-GOML2), which allows coupling to be applied regionally as well as globally, while constraining the ocean mean state in coupled regions. Compared to the standard AMIP-style MetUM atmosphere-only simulations, the MetUM-GOML2 simulations produce more monsoon LPS, which is attributed to effects of relatively small remaining (Indian Ocean) SST biases that somewhat strengthen the atmospheric monsoon base state. However, the MetUM-GOML2 simulations, all starting from the same atmospheric and oceanic base state, allow for an idealised approach to evaluate the relative effects of coupling and resolution. When the effects of SST biases are excluded, global coupling has a neutral impact on the number of LPS formed, while the associated rainfall is somewhat reduced due to a local negative air-sea feedback reducing the strength of atmospheric convection and weakening individual LPS. The MetUM-GOML2 simulations show particular sensitivity to localised coupling in the In-

Richard C. Levine · Gill M. Martin

Met Office Hadley Centre

Exeter, UK

E-mail: richard.levine@metoffice.gov.uk

Nicholas P. Klingaman · Simon C. Peatman

National Centre for Atmospheric Science-Climate

Department of Meteorology

University of Reading, Reading, UK dian and Pacific Oceans, which appears to enhance the effect of monsoon LPS. Although, in contrast to the global coupling comparison, the comparison of regionally coupled simulations is affected by both differences in interannual SST variability and SST biases, and it is likely that this causes at least part of the positive effects from Indian and Pacific Ocean coupling. More importantly, however, is that the effects of air-sea coupling are substantially smaller than the positive effects of the increase in horizontal resolution from N96 (approx. 200km) to N216 (approx. 90km). The resolution effect is also larger than that seen in older MetUM configurations.

Keywords Indian Monsoon - Global Climate Model . Low Pressure Systems · Air-sea coupling · Horizontal resolution

\section{Introduction}

Air-sea coupling and horizontal resolution are generally considered important for accurate simulations of climate and its components, for example the South Asian Summer Monsoon (SASM). In this paper the hypothesis is tested that they are important for synoptic-scale monsoon depressions and lows, which are important phenomena of the SASM. These systems contribute substantially to seasonal rainfall totals over the Indian subcontinent, while also causing many of the extreme rainfall events during the summer monsoon season (Sikka 1977; Krishnamurthy and Ajayamohan 2010; Praveen et al. 2015; Hunt et al. 2016); therefore their realistic representation is essential for climate predictions and projections on a range of time-scales.

The simulation of monsoon LPS in current climate models is often poor (Ashok et al. 2000; Sabre et al. 
2000; Stowasser et al. 2009; Praveen et al. 2015; Levine and Martin 2018), with a deficient number of LPS and associated rainfall. In atmosphere-only models this may relate to the lack of air-sea coupling, which is important in other aspects of monsoon variability (as discussed below), or to coarse horizontal resolution. An increase in horizontal resolution may provide finer-scale detail that may help to improve the organization and propagation of LPS. However, including air-sea coupling and increasing resolution also substantially increase the complexity and expense of climate model simulations, therefore it is important to understand their individual effects.

Air-sea coupling is important in determining the formation, intensity and pathway of (Indian Ocean) tropical cyclones in climate models (eg. Subrahmanyam et al. 2005). It has also been shown to be important for the climate-model simulation of monsoon interannual variability (eg. Shukla and Huang 2016 and references therein) and intra-seasonal variability, including the onset vortex (Wu et al. 2012). Air-sea coupling and intra-seasonal sea surface temperature (SST) variability support the northward propagation of the boreal summer intra-seasonal oscillation (BSISO) that is associated with monsoon active-break cycles (Fu and Wang, 2004; DeMott et al. 2014), with coupling resulting in improvements to the relationship between SST and atmospheric convection, and contributes via the effect of high-frequency SST variability on surface fluxes to an estimated $20 \%$ of the propagation of convection that is involved in the northward component of the BSISO (Gao et al. 2019). The prevalence and strength of monsoon depressions is highly correlated with active-break cycles (Krishnamurthy and Shukla, 2007), which suggests air-sea coupling may be important for the simulation of LPS, which often form, intensify and propagate over the warm summer Bay of Bengal (BoB) SSTs (Sikka 1977). Air-sea coupling may also reduce the intensity of monsoon LPS, due to local negative thermodynamic feedbacks on atmospheric convection that have been found to reduce extreme rainfall over the tropics in a similar coupled modelling setup as used in this study (Hirons et al. 2018). These feedbacks weaken local intense convection via reducing atmosphere-toocean net surface heat fluxes and increasing near-surface wind speeds, which cool the SST, reduce latent and sensible heat fluxes, and thereby weaken convection.

Coupled atmosphere-ocean configurations of the Met Office Unified Model (MetUM) generally show an increase in LPS over their atmosphere-only equivalents. However, the realistic effects of air-sea coupling alone are difficult to establish due to the development of substantial SST biases in coupled climate models, which are especially wide-spread over the northern and equatorial Indian Ocean, both of which substantially affect the mean state atmospheric monsoon (Levine et al. 2013; Levine and Turner 2012; Bollasina and Ming 2013; Bollasina and Nigam 2009), thereby highlighting the importance of correctly representing air-sea coupled feedbacks. Coupled model SST biases have also been shown to negatively affect tropical sub-seasonal variability, including the Madden-Julian Oscillation (MJO) (Klingaman and Woolnough (2014), DeMott et al. 2015) and tropical cyclones (eg. Hsu et al. 2019), and therefore may also impact monsoon LPS.

In order to minimise the effect of coupled model SST biases, new simulations are analyzed using a configuration of the MetUM atmosphere model coupled to many columns of a mixed-layer ocean (MetUM-GOML2), wherebyso ocean temperature and salinity, and therefore also SSTs, are constrained to an observed mean seasonal cycle via corrections (Hirons et al. 2015). Furthermore, the onedimensional ocean model allows air-sea coupling to be applied globally or in specific regions, allowing separation of the contributions from local and remote air-sea interactions to the representation of monsoon LPS. A further key advantage is that when the horizontal resolution of the ocean and atmosphere change, the oceanic mean state remains consistent, because the ocean mean state is constrained to observations by prescribed temperature and salinity corrections. This allows separation of the effects on monsoon LPS from changes to resolution, and from changes in the oceanic mean state. This is not possible in a fully coupled atmosphere-ocean model, where a change in resolution will also change the oceanic and atmospheric mean state.

Compared to a fully coupled atmosphere-ocean model, 148 the MetUM-GOML2 model lacks ocean dynamics, an ${ }_{149}$ important factor in SST variability. However, on syn- ${ }_{150}$ optic to sub-seasonal time-scales that are of interest ${ }_{151}$ to monsoon LPS, the SST variability over the Indian ${ }_{152}$ Ocean is largely controlled by thermodynamic processes $\quad{ }_{153}$ (e.g., Halkides et al 2015). The technique of apply- ${ }_{154}$ ing temperature and salinity corrections in MetUM- ${ }_{155}$ GOML2 could also be applied to a fully coupled atmosphereso ocean model, but the presence of interactive ocean dy- ${ }_{157}$ namics can complicate the results as the ocean dynam- $\quad 158$ ical response may lead the ocean model to drift away ${ }_{159}$ from the desired ocean mean state. In MetUM-GOML2, ${ }_{160}$ the lack of an ocean dynamical feedback to the cor- ${ }_{161}$ rections allows the effective use of imposed fixed cor- $\quad{ }_{162}$ rections. This method is not a relaxation; it is a prescribed seasonal cycle of correction terms that are obtained from an initial, separate relaxation simulation (which is not analysed in this study; see Hirons et al. 2015 for details).

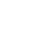

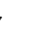
8 60 
These MetUM-GOML2 simulations have previously been used by Peatman and Klingaman (2018) to investigate the influence of air-sea coupling and horizontal resolution on the mean Indian summer monsoon and its sub-seasonal variability. While coupling over the Indian Ocean degrades the atmospheric mean state due to the presence of small remaining SST biases, there are some improvements to the northward propagation of the BSISO. Increasing the horizontal resolution from $200 \mathrm{~km}$ to $90 \mathrm{~km}$ improves the simulation of monsoon rainfall and circulation, but there are no further improvements when the resolution is increased again to $40 \mathrm{~km}$. The improvements to the intra-seasonal variability from increasing the resolution from $200 \mathrm{~km}$ to $90 \mathrm{~km}$ are found to be of similar magnitude to the improvements due to air-sea coupling over the Indian Ocean.

Previous work using an older version (Global Atmosphere (GA) 3, described in Walters et al. 2011) of the MetUM regional climate model (RCM) atmosphereonly configuration suggested that the representation of monsoon LPS can be substantially improved if biases in the large-scale flow into the Indian monsoon area are corrected (Levine and Martin 2018), while increasing the horizontal resolution from $50 \mathrm{~km}$ to $12 \mathrm{~km}$ has little effect (Karmacharya et al. 2016). Analysis of global atmosphere-only model simulations at the same MetUM version (GA3) has suggested little sensitivity of monsoon LPS to increasing the horizontal resolution from N96 $(200 \mathrm{~km})$ up to N512 $(40 \mathrm{~km})$ (Johnson et al. 2016). A newer version of the MetUM (GA6, described in Walters et al. 2017), including the new dynamical core ENDGAME, is used in this study, which may explain any difference in sensitivities.

While increased horizontal resolution may be beneficial, as seen for example in analysis of monsoon depression case studies in Numerical Weather Prediction (NWP) simulations (Hunt and Turner 2017), the studies discussed above suggest that improving the overall tropical circulation in the GCM at the standard horizontal resolution would most improve our representation of monsoon LPS. In this case the improved representation of mean SST and the monsoon circulation as a whole in MetUM-GOML2 found with increased resolution and air-sea coupling (Peatman and Klingaman, 2018) may benefit monsoon LPS as well. It is interesting to note that in most MetUM GCM experiments, and also in the general development cycle of the MetUM GCM, the strength of the mean state atmospheric monsoon circulation (and rainfall) is always positively correlated with the number of LPS (and their associated rainfall), which is also supported by CMIP5 analysis (Praveen et al. 2015). Levine and Martin (2018) suggest that a stronger mean monsoon would increase monsoon LPS, while there may be a positive feedback with more and stronger monsoon LPS strengthening the larger-scale flow into the region.

This study aims to establish whether increasing horizontal resolution, using a range typical of current GCMs, 225 and the inclusion of a simple form of air-sea coupling, over an atmosphere-only model, improves the formation, trajectories and associated rainfall of monsoon LPS.

\section{Simulations and data}

The simulations use the GA6 configuration of the MetUM atmosphere model (Walters et al. 2017).

Atmosphere-only experiments forced with observed SST use the AMIP methodology (Gates et al. 1998) and are forced with daily SST and sea-ice fractions from Reynolds et al. (2007). Fully coupled atmosphere-ocean MetUM present day control simulations use the GC2 configuration (Williams et al. 2015).

The mixed-layer ocean coupling experiments use the MetUM-GOML2 configuration (Hirons et al. 2015), whereby the vertical profiles of ocean temperature and salinity are constrained using a prescribed seasonal cycle of corrections. For all MetUM-GOML2 simulations analysed here, the ocean is constrained to the 1980-2009 climatology from Met Office ocean analyses (Smith and Murphy, 2007). The coupling can be applied selectively in space, and thereby allows coupling in individual ocean basins only without substantial changes to the ocean mean state. The resulting coupled simulations thereby minimize the effects of changes in mean SST on the atmosphere, although they still contain small SST biases (typically less than $\pm 0.5^{\circ} \mathrm{C}$, although locally can be over $\pm 1.0^{\circ} \mathrm{C}$; see Peatman and Klingaman (2018)). Due to limitations with regard to sea-ice cover, the coupling is applied over the approximate latitude band of $60^{\circ} \mathrm{S}-60^{\circ} \mathrm{N}$ (see Hirons et al. 2015, Figure 2). The lack of ocean dynamics means there is no representation of El Nino Southern Oscillation (ENSO) or Indian Ocean Dipole (IOD) variability in the ocean (Hirons et al. 2015). An indication of intraseasonal variability of SST in MetUM-GOML2 for 90km simulations (the higher horizontal resolution used in this study) is shown by Peatman and Klingaman (2018) (their Fig. 7). This shows that MetUM-GOML2 underestimates intraseasonal variability in most of the tropical Indian Ocean, with the strongest biases on the equator and in the Arabian Sea. These are both regions where ocean dynamics (upwelling) are important for SST variability. In the BoB, where most LPSs form and intensify, biases in intraseasonal SST variability are smaller and consistent with those in fully coupled GCMs. 
Further, we note that the SST variability in the free-running MetUM-GOML2 simulation analysed here does not depend on the nudging timescale applied in the initial relaxation simulation (which is not analysed in this study). The free-running MetUM-GOML2 coupled simulations are corrected only by the mean seasonal cycle of temperature and salinity corrections from the relaxation simulations. Because these are fixed corrections, not a relaxation, the corrections do not damp SST variability. Indeed, Hirons et al. (2015) noted that shortening the relaxation timescale would increase the mean bias in the free-running simulation.

Simulations at N96 (longitude $\mathrm{x}$ latitude: $1.875^{\circ} \mathrm{x}$ $1.25^{\circ}$, approximately $200 \mathrm{~km}$ at equator $)$ and $\mathrm{N} 216\left(0.83^{\circ} \mathrm{x}\right.$ $0.55^{\circ}$, approximately $90 \mathrm{~km}$ at equator) horizontal resolutions are compared. The simulations analysed are summarised in Table 1, and the notation for the simulations is discussed in the caption. Where SSTs from coupled model simulations have been used to force atmosphereonly simulations a 31-day smoothing has first been applied, following recommendations from DeMott et al. (2015).In simulations where coupling is applied regionally, climatological monthly-varying SST from Met Office ocean analyses (Smith and Murphy, 2007) are prescribed outside the coupled region. This means it is necessary to take account of interannual SST variability that is not present in the uncoupled regions, but is present in the globally coupled simulation and atmosphereonly simulation forced with either observed SST or SST from the globally coupled simulation. It is important to emphasize that the coupled regions in the MetUMGOML2 simulations do have interannual variability in SST, however, this does not organise into coupled modes like ENSO or the IOD.

The 31-day smoothing to coupled model SSTs is recommended by DeMott et al. (2015) as it has been found that applying high-frequency (e.g., daily) SST forcing in an atmosphere-only global climate model (AGCM) leads to erroneous feedbacks between surface fluxes, SSTs and convection that amplify the rainfall response to SSTs and complicate the analysis of synoptic and sub-seasonal variability. In particular, AGCM convection parametrisations respond strongly and quickly to SST variability, such that in an AGCM, high-frequency warm SST anomalies are collocated with enhanced surface fluxes and high precipitation; high-frequency cold SST anomalies are collocated with reduced surface fluxes and low precipitation. The 31-day smoothing approach is further justified by the work of Hirons et al. (2018), who demonstrated that an AGCM with high-frequency SSTs overestimated precipitation extremes, relative to satellite-derived responses.
Tracking of monsoon LPS is carried out using TRACK 324 software (Hodges 1994) with additional criteria specifi- ${ }_{325}$ cally for Indian monsoon LPS following the methodol- 326 ogy described in Levine and Martin (2018). The track- ${ }_{327}$ ing is carried out by first filtering the vorticity data to a 328 common T42 resolution in all cases, therefore there is no 329 resolution dependence in the tracking method (Hodges 330 1994; Levine and Martin 2018).

ERA5 (ERA5; Copernicus Climate Change Service (C3S) (2017)) re-analysis data of $850 \mathrm{hPa}$ winds on a 6-hourly time-scale and at $0.25^{\circ} \times 0.25^{\circ}$ horizontal resolution are used for diagnosing monsoon LPS in observations and monthly mean ERA5 data for atmospheric winds, temperature and relative humidity are used for model comparison. Observational data for precipitation are taken from the APHRODITE data-set (Yatagai et al. 2009), as this has sufficiently high temporal (daily) and spatial $\left(0.25^{\circ}\right)$ resolution, although does not include coverage over the ocean, and currently only reaches up to 2007. Therefore, the observational data of the LPS tracks is analysed for the 1983-2007 period, which is still sufficient to compute a climatological average of monsoon LPS rainfall for comparison with the model data. GPCP monthly mean precipitation is used for evaluating the wider area mean conditions in the simulations (Adler et al 2003).

\section{Results}

3.1 Reanalysis and observations

We start by discussing the LPS detected in the ERA5 re-analysis, before moving to a comparison with the model simulations. Properties of these tracks combined with APHRODITE rainfall data are shown in Fig. 1. The track density in this figure is calculated as

$\rho_{i, j}=\left[\sum_{t} \delta_{i, j, t}\right] /\left[\sum_{i, j} \sum_{t} \delta_{i, j, t}\right]$

where $\delta=1$ if a track is present at $(i, j, t)$ or $\delta=0$ otherwise, for all 6-hourly time-steps during LPS lifetimes. The coordinates $i, j$ and $t$ represent longitude, latitude and time respectively. Genesis density is calculated in a similar fashion:

$\phi_{i, j}=\left[\sum_{\mathrm{LPS}} \delta_{i, j, t_{0}}\right] /\left[\sum_{i, j} \sum_{\mathrm{LPS}} \delta_{i, j, t_{0}}\right]$

where $t_{0}$ is the first time-step for each LPS.

There are 212 LPS diagnosed in ERA5 in the 19832007 period during June to September, which is equivalent to almost 8.5 systems per monsoon season. The
26 227 28 30 
Table 1 List of simulations. $A T M$ represents an atmosphere-only simulation. $G L$ represents the MetUM-GOML2 globally coupled simulation. Regionally coupled MetUM-GOML2 simulations are represented by $I O$ (Indian Ocean), PO (Pacific Ocean), $A O$ (Atlantic Ocean), IO_PO (Indian and Pacific Oceans), etc. GC2 represents the fully coupled MetUM-GC2 configuration simulation. Sub-scripts show the horizontal resolution in $\mathrm{km}$ (either $200 \mathrm{~km}$ or $90 \mathrm{~km}$ ). The value in brackets for atmosphere-only simulations indicates the SST used ([obs] for observational SST, $[G L]$ for MetUM-GOML2 globally coupled SST, $[I O]$ for MetUM-GOML2 Indian Ocean coupled SST, etc.)

\begin{tabular}{|c|c|c|c|}
\hline Description & Atmosphere-Ocean Coupling & (MetUM) Resolution & Years \\
\hline$A T M_{200}[o b s]$ & None - AMIP run (obs SST) & $200 \mathrm{~km}(\mathrm{~N} 96)$ & $1983-2010$ \\
\hline$A T M_{90}[o b s]$ & None - AMIP run (obs SST) & $90 \mathrm{~km}(\mathrm{~N} 216)$ & $1983-2010$ \\
\hline$G C 2_{200}$ & Fully 3D coupled MetUM & $200 \mathrm{~km}(\mathrm{~N} 96)$ & 28 years (present day control run) \\
\hline$G C 2_{90}$ & Fully 3D coupled MetUM & $90 \mathrm{~km}(\mathrm{~N} 216)$ & 28 years (present day control run) \\
\hline$G L_{200}$ & GOML2 Global (constrained to obs) & $200 \mathrm{~km}(\mathrm{~N} 96)$ & 28 years \\
\hline $\mathrm{AO}_{-} \mathrm{PO}_{200}$ & GOML2 Global, EXCEPT Indian Ocean & $200 \mathrm{~km}(\mathrm{~N} 96)$ & 28 years \\
\hline $\mathrm{IO}_{200}$ & GOML2 Indian Ocean only & $200 \mathrm{~km}(\mathrm{~N} 96)$ & 28 years \\
\hline $\mathrm{PO}_{200}$ & GOML2 Pacific Ocean only & $200 \mathrm{~km}(\mathrm{~N} 96)$ & 28 years \\
\hline$I_{-} P_{2} O_{200}$ & GOML2 Indian and Pacific Oceans & $200 \mathrm{~km}(\mathrm{~N} 96)$ & 28 years \\
\hline$A T M_{200}[I O]$ & None - SSTs from $I O_{200}$ (31-day smoothed) & $200 \mathrm{~km}(\mathrm{~N} 96)$ & 28 years \\
\hline$A T M_{200}[G L]$ & None - SSTs from $G L_{200}$ (31-day smoothed) & $200 \mathrm{~km}(\mathrm{~N} 96)$ & 28 years \\
\hline$G L_{90}$ & GOML2 Global (constrained to obs) & $90 \mathrm{~km}(\mathrm{~N} 216)$ & 28 years \\
\hline $\mathrm{AO}_{-} \mathrm{PO}_{90}$ & GOML2 Global EXCEPT Indian Ocean & $90 \mathrm{~km}(\mathrm{~N} 216)$ & 28 years \\
\hline$I O_{90}$ & GOML2 Indian Ocean only & $90 \mathrm{~km}(\mathrm{~N} 216)$ & 28 years \\
\hline $\mathrm{PO}_{90}$ & GOML2 Pacific Ocean only & $90 \mathrm{~km}(\mathrm{~N} 216)$ & 28 years \\
\hline$I_{-} P_{90}$ & GOML2 Indian and Pacific Oceans & $90 \mathrm{~km}(\mathrm{~N} 216)$ & 28 years \\
\hline$A T M_{90}[I O]$ & None - SSTs from $I O_{90}$ (31-day smoothed) & $90 \mathrm{~km}(\mathrm{~N} 216)$ & 28 years \\
\hline$A T M_{90}[G L]$ & None - SSTs from $G L_{90}$ (31-day smoothed) & $90 \mathrm{~km}(\mathrm{~N} 216)$ & 28 years \\
\hline ERA5/APHRO & atm $\mathrm{U}, \mathrm{V}, \mathrm{T}, \mathrm{RH}$ from re-analysis / obs land-only precip & $0.25^{\circ} / 0.25^{\circ}$ & $1983-2007$ \\
\hline
\end{tabular}

systems mainly originate in the northern Bay of Bengal, with further systems developing within the monsoon trough over north eastern India. During the early monsoon a small number of cyclonic systems develop over the eastern Arabian Sea. The combined effects of the LPS contribute a substantial amount of rainfall to the north-eastern and northern areas of India.

\subsection{Standard MetUM simulations and MetUM-GOML2 SST biases}

In this section results are presented from standard AMIPstyle atmosphere only simulations forced with observed SST (ATM $[o b s])$ and fully coupled atmosphere-ocean simulations $(G C 2)$. The $G C 2$ simulations have substantial SST biases, both local and remote to the Indian Ocean sector (eg. Fig. 2a in Wainwright et al. 2019). Effects of local Indian Ocean SST biases on the Indian monsoon have been shown for a previous version of the MetUM in Levine and Turner (2012), with northern Indian Ocean and equatorial Indian Ocean cold SST biases having counteracting effects. However, the cold SST bias over the Arabian Sea dominated in that particular version of the model, resulting in weakened monsoon winds and rainfall. This pattern of cold SST biases, although smaller in magnitude, is still persistent in the $G C 2$ configuration used in this study, but it appears that there is less influence from the cold bias over the Arabian Sea.

The SST biases in the MetUM-GOML2 simulations discussed in this study are shown in Fig. 2. This shows that there is still a cold SST bias present over the equatorial Indian Ocean at both horizontal resolutions, which may influence the Indian monsoon and LPS. A direct impact of this could be to strengthen the monsoon circulation, as expected from experiments using a previous configuration of the MetUM (Levine and Turner, 2012). However, differences in the magnitude or area of the SST bias may result in other impacts, while other models may behave differently (Bollasina and Nigam 2009; Prodhomme et al. 2014). There is also the potential for remote SST biases over the Atlantic or Pacific Oceans to influence the monsoon indirectly through atmospheric teleconnections.

The cold SST biases in the Indian Ocean are primarily the result of errors in atmospheric wind-stress forcing of the ocean, which cannot be eliminated using the temperature and salinity corrections. Excessive wind-driven oceanic vertical mixing cools SST, but also means that the temperature corrections applied are too readily mixed. The temperature corrections attempt to restratify the ocean and shoal the mixed layer - by warming near the surface and cooling at depth - but these corrections are ineffective as they are mixed across the (deeper) mixed layer by the atmospheric wind forcing. The strength of the cold SST biases does not depend strongly on the nudging timescale used in the initial MetUM-GOML2 relaxation simulation. Shortening the nudging timescale would strengthen the temperature corrections, but retain their vertical profile - warming near the surface and cooling at depth - resulting in nearly zero net change to oceanic heat content and hence similar biases in SST and mixed-layer depth. For further details, see Hirons et al. (2015). 

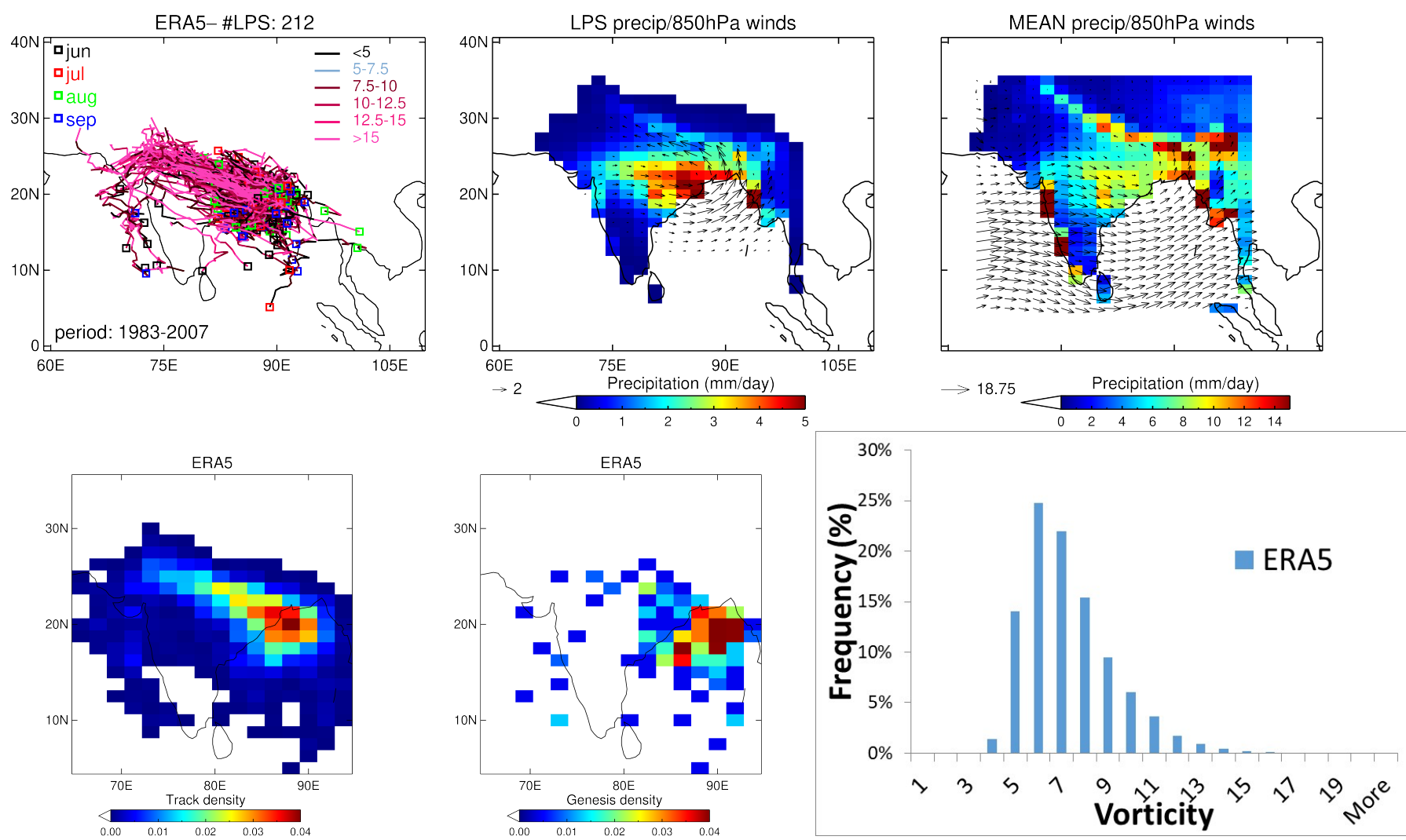

Fig. 1 Monsoon LPS diagnosed in ERA5 re-analysis for 1983-2007 with APHRODITE land precipitation statistics. On the top row: the first panel on left hand-side shows LPS trajectories with the total number of LPS in title. The coloured squares indicate the starting point and month of each track. The colour of the trajectories indicates the strength in terms of relative vorticity $\left(10^{-5} s^{-1}\right.$ at native resolution). The second panel from left shows LPS contribution to JJAS seasonal mean precipitation (mm/day) and $850 \mathrm{hPa}$ winds (m/s, black vectors). The third panel from left shows Jun-Sept seasonal mean precipitation $\left(\mathrm{mm} /\right.$ day) and $850 \mathrm{hPa}$ winds $\left(\mathrm{m} / \mathrm{s}\right.$, black vectors). All data is plotted on a $200 \mathrm{~km}\left(\mathrm{~N} 96 ; 1.875^{\circ} \times 1.25^{\circ}\right)$ grid. Bottom row shows TRACK DENSITY, GENESIS DENSITY and a HISTOGRAM of LPS intensity. The intensity is shown in terms of relative vorticity (in units of $10^{-5} s^{-1}$ ) filtered to T42 resolution (as used in tracking) at the centre of the system at the $850 \mathrm{hPa}$ level, and includes all 6-hourly time-steps during LPS lifetime. These ERA5 figures have been generated using Copernicus Climate Change Service Information 2020.

The results of LPS analysis for $A T M_{90}[o b s], G C_{90}$, $G L_{90}$ and $A T M_{90}[G L]$ are shown in Fig. 3. An equivalent comparison for the $200 \mathrm{~km}$ (N96) simulations has qualitatively similar results and is not shown. The MetUM simulations have substantially less LPS activity than ERA5, while activity is far more spatially limited to the Bay of Bengal, with only a few systems travelling westwards across India in the monsoon trough. This lack of LPS in global simulations, and the inability to propagate over Indian land, is a typical feature of MetUM climate configurations (Levine and Martin, 2018). The $A T M_{90}[o b s]$ has only 76 LPS, or 2.7 LPS per season, which is approximately $32 \%$ of the number in ERA5. This coincides with the consistently weak monsoon in the MetUM (e.g. Johnson et al. 2016). The fully coupled $G C 2_{90}$ simulation has a few more systems and associated LPS rainfall, which coincides with stronger westerly low-level winds across the Arabian
Sea, India and the Bay of Bengal. There is also more rainfall across this band, although not much over Indian land. Differences between $G C_{90}$ and $A T M_{90}[o b s]$ could be due to many factors, including direct effects of coupling on LPS, local or remote effects of coupling on the monsoon circulation, direct effects of local SST biases on LPS, or local or remote effects of SST biases on the monsoon circulation.

The MetUM-GOML2 mixed-layer ocean coupled sim- ${ }_{456}$ ulation $G L_{90}$ shows quite similar changes to $G C 2_{90}$, though there are now substantially more systems (4.4 on average per season, or approximately half of the number in ERA5). This coincides with more LPS rainfall, which now also starts to show some impact on mean rainfall over NE India. There could be numerous reasons for the differences with $G C 2_{90}$, for example a local impact could be the strengthening of the monsoon circulation due to a change in the balance of northern 

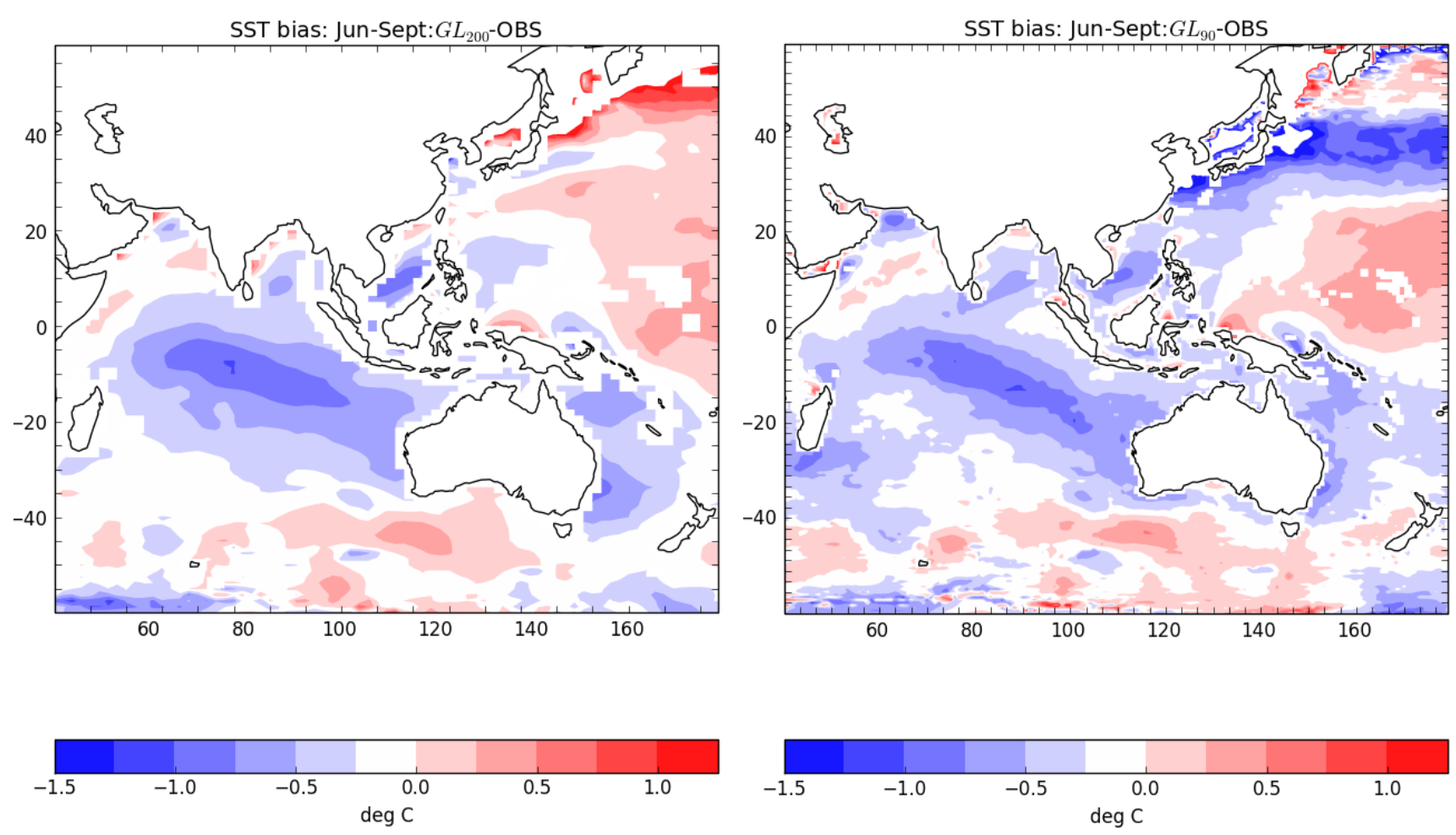

Fig. 2 Climatological JJAS SST biases for $G L_{200}$ and $G L_{90}$ compared to Smith and Murphy (2007) observations.

and equatorial Indian Ocean SST biases, thereby providing more favourable conditions for LPS formation. The comparison with $A T M_{90}[G L]$ allows some more definite conclusions on the effects of SST biases. The $A T M_{90}[G L]$ simulation is very close to $G L_{90}$ in terms of differences with the $A T M_{90}[o b s]$ standard AMIP-type simulation. This suggests that coupling is not a major influence in the changes seen in the latter three rows of 3 with respect to $A T M_{90}[o b s]$, which therefore are quite likely the result of SST biases. It should be noted that the AMIP-type runs also contain variability due to ENSO and IOD events in the SST forcing, while the atmosphere-only runs forced with the coupled SST do not contain such variability due to the smoothing applied. This is likely to affect the interannual variability in LPS and may also affect the mean number of LPS due to non-linear effects.

It is also worth noting that Peatman and Klingaman (2018) has investigated the role of intra-seasonal variability (ISV), interannual variability (IAV) and SST biases in differences in the mean state atmosphere presented due to coupling in different basins, and it is concluded that these are mainly attributable to SST biases. The $G L$ - AO_PO differences (Peatman and Klingaman (2018), Figs. 3a,c) then give an approximation of the effects of Indian Ocean SST biases, which are to cause a relative reduction of precipitation over the equatorial Indian Ocean and increase to the north of this, while there are no significant changes over Indian land. This is accompanied by strengthening of the low-level monsoon jet starting from the Bay of Bengal and extending through the South China Sea into the W Pacific. While the latter is consistent with the effects seen in this study (Fig. 3, note different scales) in $A T M[G L]-A T M[o b s]$, the biases in the mean state precipitation in this case are more widespread and larger than the aforementioned $G L-A O \_P O$ changes in Peatman and Klingaman (2018), which must then be explained by effects of missing IAV and/or ISV in the $A T M[G L]$ experiments and possibly the role of any of these processes feeding back on each other.

The precise attribution of changes to the monsoon circulation and LPS to localised SST biases and their mechanisms is beyond the scope of this study. However, while the atmospheric monsoon base state may be slightly different from the standard fully coupled and AMIP-style MetUM simulations, the isolated comparison of MetUM-GOML2 mixed-layer ocean coupled simulations and their equivalent atmosphere-only simulations (forced with GOML2 SST) does provide for a somewhat idealised decomposition into effects from coupling and from resolution. 

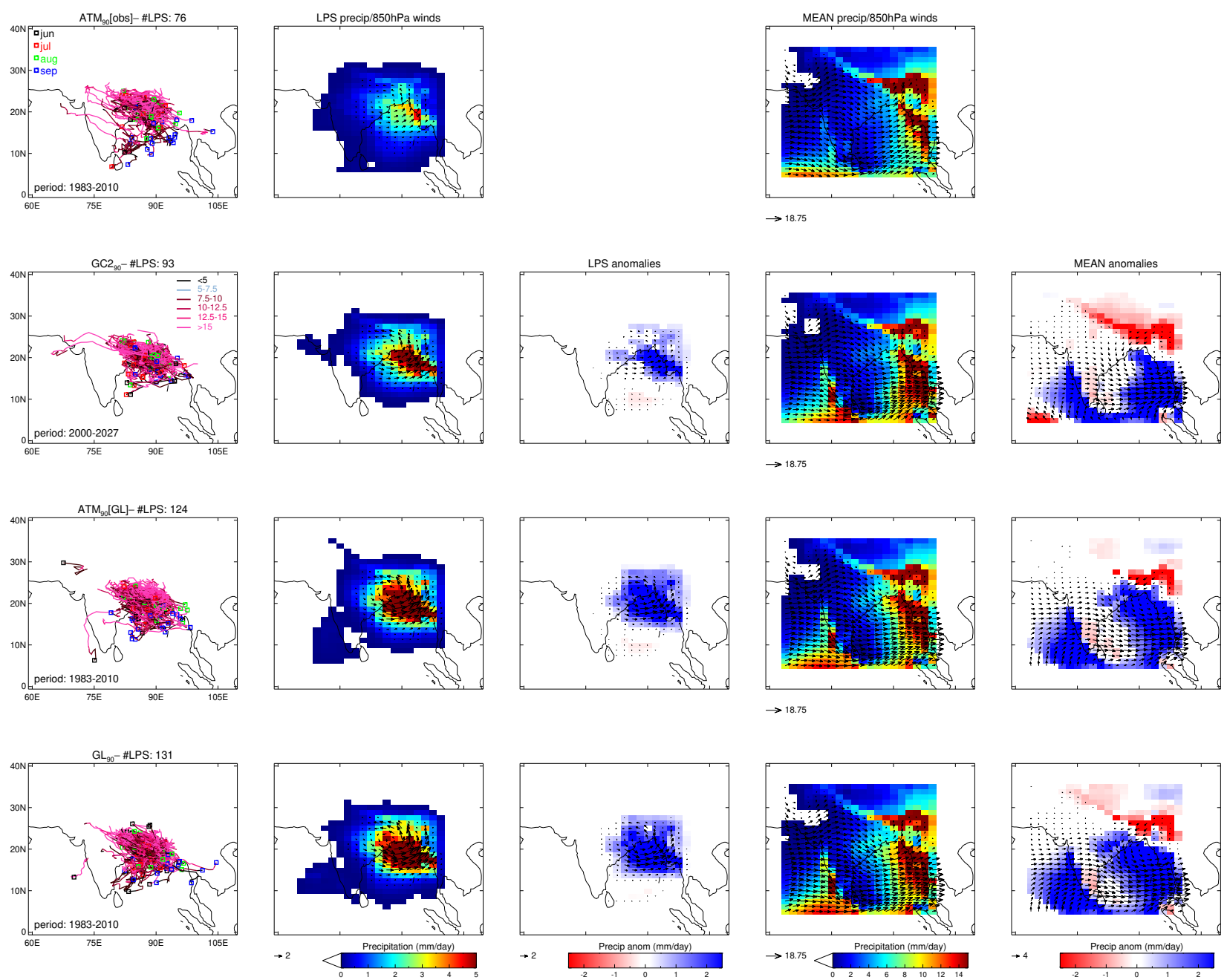

Fig. 3 Monsoon LPS diagnosed in 90km (N216) experiments for 1983-2010 period. Top row shows the ATM $M_{90}[o b s]$ experiment, with subsequent rows showing results for $G C 2_{90}, G L_{90}$ and $A T M_{90}[G L]$. Differences are all in comparison to $A T M_{90}[o b s]$. The first panel on left hand-side shows LPS trajectories with the total number of LPS in title. The coloured squares indicate the starting point and month of each track. The colour of the trajectories indicates the strength in terms of relative vorticity $\left(10^{-5} s^{-1}\right.$ at native resolution). The second panel from left shows LPS contribution to JJAS seasonal mean precipitation $(\mathrm{mm} /$ day $)$ and $850 \mathrm{hPa}$ winds (m/s, black vectors). The third panel from left shows difference in LPS precipitation and $850 \mathrm{hPa}$ wind contributions with respect to top row experiment. The fourth panel from left shows Jun-Sept seasonal mean precipitation (mm/day) and $850 \mathrm{hPa}$ winds (m/s, black vectors). The fifth panel from left shows difference in Jun-Sept seasonal mean and $850 \mathrm{hPa}$ wind contributions with respect to top row experiment. Data are plotted on a common $200 \mathrm{~km}$ $\left(\mathrm{N} 96 ; 1.875^{\circ} \times 1.25^{\circ}\right)$ grid. Only significant differences and vectors at $90 \%$ level using a student t-test are shown. Values exceeding the colour scale maxima are capped at the relevant maximum colour value.

\subsection{Role of air-sea coupling}

In order to isolate the effects of the air-sea coupling, each coupled simulation is compared to the equivalent atmosphere-only simulation forced with (31-day smoothed) SSTs from the coupled simulation. In this way, for example, the $G L_{200}$ simulation should be compared to $A T M_{200}[G L]$. However, we also compare against the atmosphere-only simulation forced with observed SSTs in order to interpret the results from the regionallycoupled simulations.

\subsubsection{Global coupling}

The number of monsoon LPS in $G L_{200}$ (81, equivalent ${ }_{529}$ to 2.9 LPS per JJAS season on average) and $A T M_{200}[G L]{ }_{530}$ (75, equivalent to 2.7 LPS per season on average) is ${ }_{53}$ similar, though there is an eastward shift visible in the ${ }_{532}$ location of the LPS trajectories and the resulting rain- 
fall in $G L_{200}$ (Fig. 4). In the coupled simulation the LPS appear to produce marginally less rainfall, while the trajectories and rainfall are somewhat more constrained over the Bay of Bengal and do not move as far westwards across northern India as in observations. This reduced rainfall over the monsoon trough helps explain the differences between these simulations in the mean seasonal JJAS rainfall, the main feature of which is weaker rainfall over much of India and the $\mathrm{BoB}$ in $G L_{200}$. The comparison of $G L_{200}$ with $A T M_{200}[o b s]$ in Fig. 4 further highlights that the combined effect of differences in interannual SST variability and SST biases in $G L_{200}$ results in a strengthening of the seasonal mean monsoon and increased LPS activity in $G L_{200}$. This is an important consideration when interpreting the locally coupled simulations in later sections.

The percentage of seasonal rainfall change due to changes in LPS is shown in Fig. 5. This is calculated as $\Delta=100 \% \times\left[\frac{\operatorname{Pr}_{\mathrm{LPS}}(G L)-\operatorname{Pr}_{\mathrm{LPS}}(A T M[G L])}{\operatorname{Pr}(G L)-\operatorname{Pr}(A T M[G L])}\right]$,

where $P r$ is mean JJAS precipitation and $P r_{\mathrm{LPS}}$ is LPS rainfall over the same period.

This highlights that the changes over India and the $\mathrm{BoB}$ are to a large degree attributable to LPS. The damping effect of air-sea coupling on LPS rainfall over the $\mathrm{BoB}$ is consistent with the localised effect of air-sea coupling on tropical rainfall seen in previous studies (eg. Hirons et al. 2018).

Both 200km (N96) MetUM simulations have substantially fewer LPS and less LPS rainfall than diagnosed in ERA5 and APHRODITE (cf. Fig. 1). The trajectories in the re-analysis also reach substantially further westwards across northern India within the monsoon trough. This lack of LPS in global simulations, and the inability to propagate over Indian land, is a typical feature of MetUM climate configurations (Levine and Martin, 2018).

These common biases in LPS representation with respect to observations/reanalysis are likely the result of the overall weak monsoon circulation in this configuration as also seen in AMIP-style simulations in previous configurations of the MetUM (eg. Johnson et al. 2016). The relatively weak Somali Jet, the lack of rainfall over India, the excessive rainfall over the equatorial Indian Ocean and Himalayan foothills are all part of this, and make for unfavourable conditions for LPS formation and westward propagation over the relatively dry Indian land. It has been shown in Levine and Martin (2018) using regional climate model simulations that substantial improvements are seen when the inflow conditions into the Indian sector are corrected, including the probable effect of pre-cursor disturbances from the W Pacific.

\subsubsection{Coupling in individual basins}

In this section the effect of coupling in individual basins is examined in the $200 \mathrm{~km}$ (N96) simulations (Figure 6). Among these simulations, the global coupling experiment produces the most LPS, which appear to play a role in differences in seasonal-mean precipitation over Indian land. On the other hand, the experiments without coupling over the Indian Ocean produce the fewest LPS and least LPS rainfall, suggesting local coupling is important for Indian monsoon LPS formation.

The effects of coupling will be examined two ways, using two different reference states. The first uses $G L_{200}$ as the reference simulation. In this way we examine the contribution to the overall effect of global coupling from the following four areas:

1. Coupling INSIDE Indian Ocean only: $G L_{200}$ $A O \_P O_{200}$ (Fig. 6, second row),

2. Coupling OUTSIDE Indian Ocean: $G L_{200}$ $I O_{200}$ (Fig. 6, third row),

3. Coupling OUTSIDE Pacific Ocean: $G L_{200}$ $\mathrm{PO}_{200}$ (Fig. 6, fourth row),

4. Coupling OUTSIDE Indian and Pacific Oceans: $G L_{200}$ - $I O \_P O_{200}$ (Fig. 6, fifth row).

The first of these $\left(G L_{200}-A_{-} P O_{200}\right)$ indicates the effect of adding Indian Ocean coupling in comparison to a base state where (i) there is already air-sea coupling in the Atlantic and Pacific Oceans; (ii) there are MetUM-GOML2 mean SST biases in all three basins (Indian, Pacific and Atlantic Oceans); and (iii) there are no coupled modes of variability like ENSO or the IOD.

In general, the contribution from coupling over the Indian Ocean $\left(G L_{200}-A_{-} P O_{200}\right)$ to the effects of global coupling on Indian monsoon LPS rainfall is similar, and of the same sign, to that from coupling outside the Indian Ocean $\left(G L_{200}-I O_{200}\right)$. This suggests that both coupling within and outside the Indian Ocean have a positive effect of similar magnitude, which is particularly evident in monsoon LPS rainfall. In terms of JJAS mean rainfall, in addition to the effects over India and the BoB from the monsoon LPS, there is a more widespread positive effect from coupling within the Indian Ocean on rainfall over the Arabian Sea, BoB and equatorial Indian Ocean.

Of the other areas shown, there is a neutral effect from coupling outside the Indian and Pacific Oceans $\left(G L_{200}-I O_{-} P O_{200}\right)$. This suggests that the positive effects from coupling outside the Indian Ocean $\left(G L_{200}\right.$ - $I O_{200}$ ), as discussed earlier, are primarily due to effects of coupling over the Pacific Ocean. Furthermore, the effects of coupling outside the Pacific Ocean $\left(G L_{200}\right.$ 

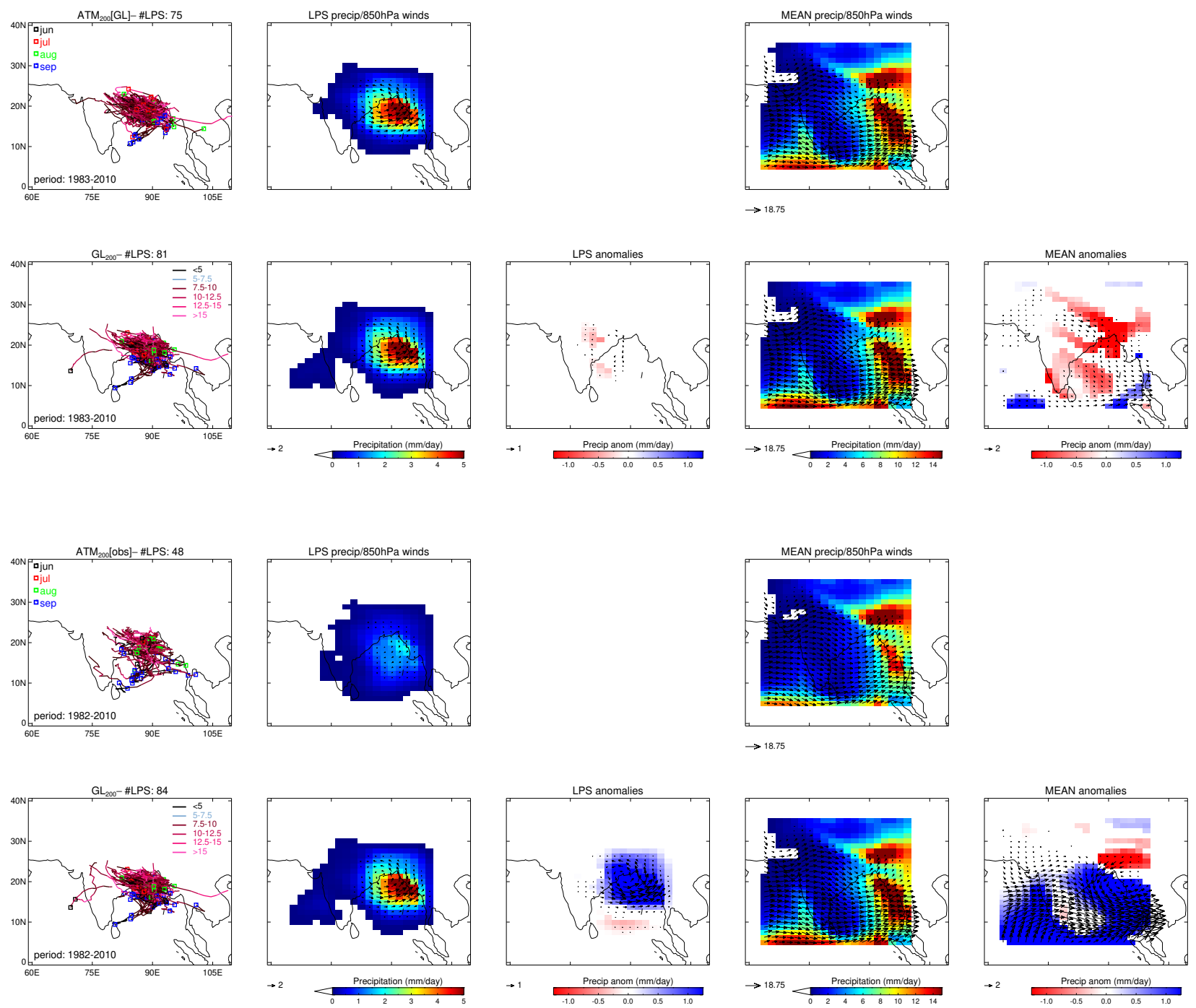

Fig. 4 Monsoon LPS diagnosed in 200km (N96) experiments for 1983-2010 period. Top row shows the $A T M_{200}[G L]$ experiment, second row shows the $G L_{200}$ experiment, with differences displayed as $\left[G L_{200}-A T M_{200}[G L]\right]$. The same comparison is shown for $G L_{200}$ with $A T M_{200}[o b s]$ in the third and fourth rows. The first panel on left hand-side shows LPS trajectories with the total number of LPS in title. The coloured squares indicate the starting point and month of each track. The colour of the trajectories indicates the strength in terms of relative vorticity $\left(10^{-5} s^{-1}\right.$ at native resolution). The second panel from left shows LPS contribution to JJAS seasonal mean precipitation ( $\mathrm{mm} /$ day) and $850 \mathrm{hPa}$ winds $(\mathrm{m} / \mathrm{s}$, black vectors). The third panel from left shows difference in LPS precipitation and $850 \mathrm{hPa}$ wind contributions with respect to top row experiment. The fourth panel from left shows Jun-Sept seasonal mean precipitation (mm/day) and $850 \mathrm{hPa}$ winds (m/s, black vectors). The fifth panel from left shows difference in Jun-Sept seasonal mean and $850 \mathrm{hPa}$ wind contributions with respect to top row experiment. All data in panels two, three, four and five are plotted on a common $200 \mathrm{~km}\left(\mathrm{~N} 96 ; 1.875^{\circ} \times 1.25^{\circ}\right)$ grid. Only significant differences and vectors at $90 \%$ level using a student t-test are shown. Values exceeding the colour scale maxima are capped at the relevant maximum colour value.

- $P O_{200}$ are very similar to the effects of coupling outside the Indian Ocean $\left(G L_{200}-I O_{200}\right)$.

However, it is important to note that these (apparent positive) effects are of the opposite sign to the $G L_{200}-A T M_{200}[G L]$ comparison, which suggested a neutral-negative effect of global coupling when referenced to the equivalent atmosphere-only simulation. This discrepancy can occur due to various reasons. Firstly, the uncoupled regions in $I O_{200}, P O_{200}$, etc. are prescribed with climatological monthly-varying observed SST, which does not contain interannual SST variability that is present in the globally coupled simulation and the atmosphere-only simulation forced with SST from the globally coupled simulation. Secondly, the re- 

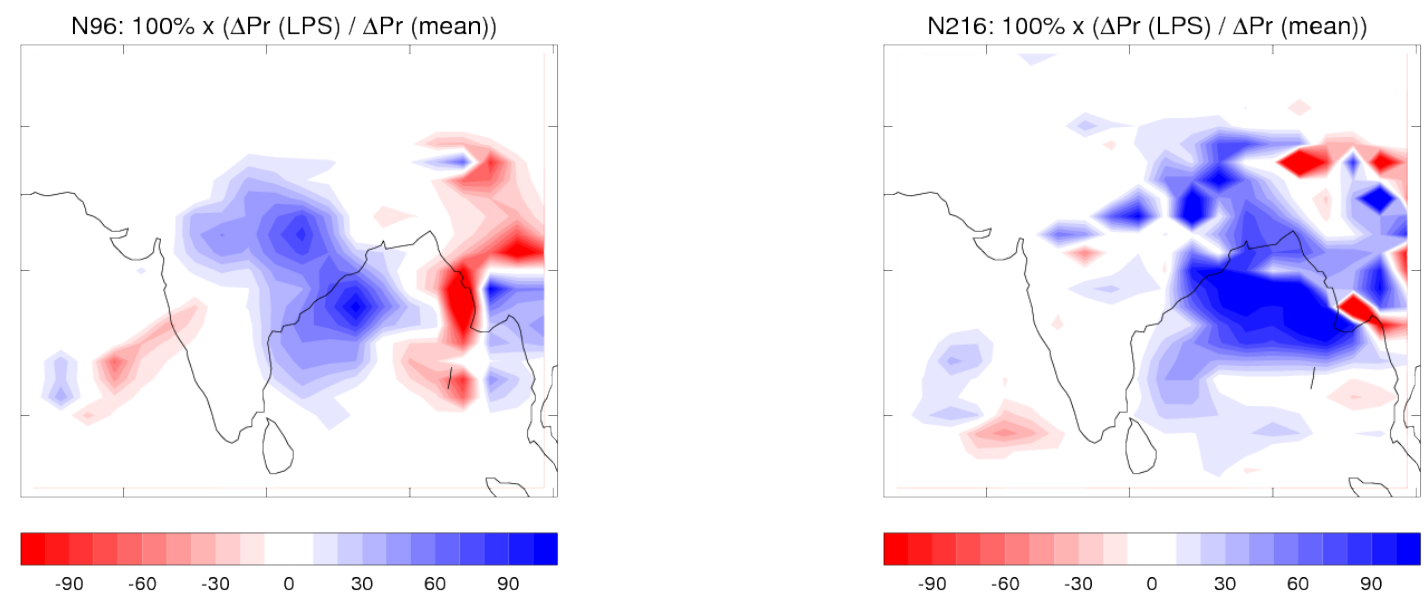

Fig. 5 Percentage of seasonal change in rainfall due to LPS in N96 (200km, on left) and N216 (90km, on right) global coupling experiments. Calculated as in eq. 3. Grid-boxes where mean precipitation change $\mid \operatorname{Pr}(G L)-\operatorname{Pr}(A T M[G L] \mid<0.1 \mathrm{~mm} /$ day have been masked out (set to zero). Note that values can exceed $\pm 100 \%$ due to compounding/compensating changes in mean rainfall from sources other than LPS.

maining SST biases in the globally coupled simulation are not present in the uncoupled regions of the regionally coupled simulations. The $G L_{200}-A T M_{200}[o b s]$ comparison in Fig. 4, which shows a strengthening of the monsoon and LPS in $G L_{200}$ due to differences in interannual SST variability and SST bias, suggests that the positive signals found in the previous comparison of the locally coupled simulations may be (at least partly) for the same reason. Thirdly, there may be interaction between the effects of coupling in different basins. However, it should be emphasized that the first two factors do not affect the $G L_{200}-A T M_{200}[G L]$ comparison.

The second comparison uses $A T M_{200}[o b s]$ as the reference simulation in order to examine the effect of coupling in each of the different regions versus no coupling at all. In this case the mean SST in the uncoupled regions (climatological monthly-varying observed SST from Met Office ocean analyses) remains relatively consistent in all the simulations with the observed SST from Reynolds et al. (2007) in the atmosphere-only AMIP-type run $\left(A T M_{200}[o b s]\right)$. Global coupling $\left(G L_{200}-\right.$ $A T M_{200}[o b s]$ has already been shown in this manner in Fig. 4.

5. Coupling INSIDE Atlantic and Pacific Oceans: $A O_{-} P O_{200}-A T M_{200}[o b s]$ (Fig. 7, second row),

6. Coupling INSIDE Indian Ocean only: $I O_{200}$ $A T M_{200}[o b s]$ (Fig. 7, third row),

7. Coupling INSIDE Pacific Ocean only: $P O_{200}$ - $A T M_{200}[o b s]$ (Fig. 7, fourth row),

8. Coupling INSIDE Indian and Pacific Oceans: $I O \_P O_{200}-A T M_{200}[o b s]$ (Fig. 7, fifth row).

For example, the $I O_{200}-A T M_{200}[o b s]$ comparison indicates the effect of adding Indian Ocean coupling compared to a base state where (i) the Atlantic and Pacific Oceans are not coupled; (ii) the mean SST in the Atlantic and Pacific Oceans is similar to observed; and (iii) there are coupled modes of variability like ENSO present.

The results suggest that the combined Indian and Pacific Ocean coupling IO_PO $O_{200}-A T M_{200}[o b s]$ has the largest effect, similar but slightly weaker than the equivalent global coupling response $G L_{200}-A T M_{200}[o b s]$ (Fig. 4), while the biggest single influence comes from Indian Ocean coupling. Differences between the two comparisons of coupling inside the Indian Ocean $\left(G L_{200}\right.$ - AO_PO $O_{200}$ and $I O_{200}-A T M_{200}[o b s]$ are relatively small, and may reflect the effect of differences in interannual SST variability between the reference simulations.

In summary, while there are the caveats with respect to differences in SST biases and variability, both comparisons point to the largest sensitivity coming from air-sea coupling in the Indian Ocean and Pacific Ocean basins.

\subsection{Role of horizontal resolution}

\subsubsection{Impact of increase in horizontal resolution}

The $A T M_{90}$ and $G L_{90}$ higher resolution simulations are compared to the observations in Fig. 8. The main feature is that the increase in resolution from $200 \mathrm{~km}$ (N96) to $90 \mathrm{~km}$ (N216) results in substantially more LPS activity and increased LPS rainfall (cf. Fig. 4). The number of monsoon LPS in $G L_{90}$ is 131 (equivalent to 4.7 LPS per JJAS season on average), while $A T M_{90}[G L]$ 



Fig. 6 Coupling sensitivity of $200 \mathrm{~km}$ (N96) simulations for 1983-2010 period. Top row shows the Global Coupling (obs) experiment, while subsequent rows show the results for regional coupling and differences displayed as $\left[G L_{200}-A O_{-} P O_{200}\right]$ (coupling INSIDE Indian Ocean), $\left[G L_{200}-I O_{200}\right]$ (coupling OUTSIDE Indian Ocean), $\left[G L_{200}-P O_{200}\right]$ (coupling OUTSIDE Pacific Ocean), $\left[G L_{200}-I O_{-} P O_{200}\right]$ (coupling OUTSIDE Indian and Pacific Oceans). The layout of the plots is as described in Fig. 4.

has a similar number (124, equivalent to 4.4 LPS per season on average). These are closer to the observed number (6.8 per JJAS season) than the lower resolution $200 \mathrm{~km}$ (N96) simulations. As stated previously, the results from the LPS tracking are independent of resolution, therefore the improvements at higher resolution are due to the model capturing the LPS more accu- rately. In both the atmosphere-only and coupled $90 \mathrm{~km}$ (N216) simulations the systems form over a larger area of the $\mathrm{BoB}$ than is the case for the $200 \mathrm{~km}$ (N96) simulations, which is somewhat more in line with observations. The LPS are also somewhat more realistic as they travel further north-westwards across the $\mathrm{BoB}$ and northern India at higher resolution. 

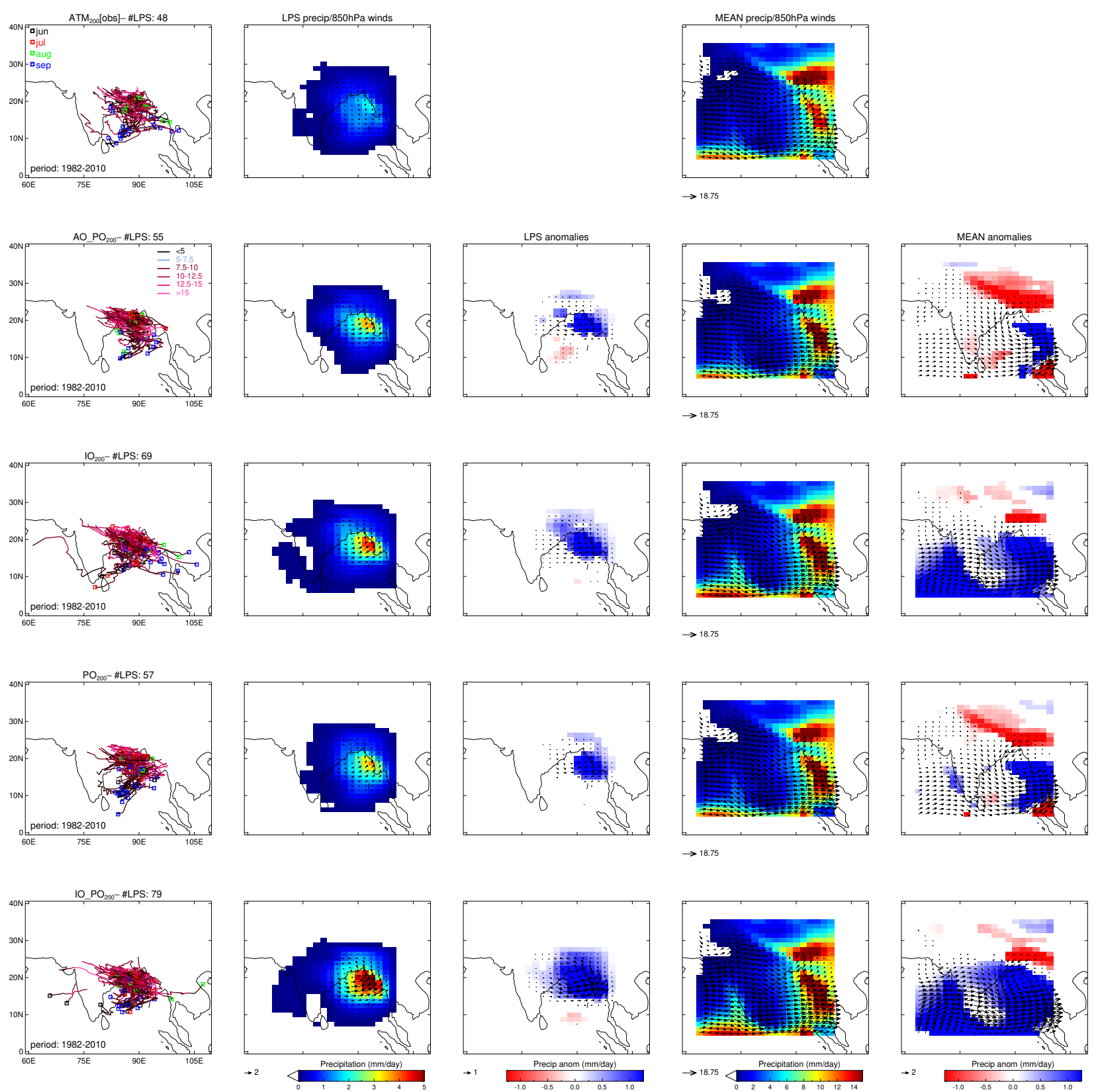

Fig. 7 Coupling sensitivity of 200km (N96) simulations for 1983-2010 period. Top row shows the Atmosphere-only experiment, while subsequent rows show the results for regional coupling and differences displayed in the following form $[I O 200]-A T M_{200}[o b s]$. The layout of the plots is as described in Fig. 4.

There are several factors which likely combine to result in the improvements with increased horizontal resolution. Firstly, better resolving the structure of the LPS. Using the same MetUM configuration (GA6) using initialised NWP simulations of monsoon depressions, Hunt and Turner (2017) found the greatest improvements with changes in horizontal resolution when moving from N96 (denoted in this paper as 200km) to $\mathrm{N} 216$ (denoted in this paper as $90 \mathrm{~km}$ ), with little improvement beyond that. This indicates that there should be an improvement in resolving the structure of the LPS in our higher resolution simulations.

The second factor is improvement to the wider region circulation. Levine and Martin (2018) and Karmacharya et al $(2015,2016)$, using an older configuration of the MetUM (GA3, without the ENDGAME dynamical core improvements in GA6), found that horizontal resolution (in this case from $50 \mathrm{~km}$ to $12 \mathrm{~km}$ ) plays 
a smaller role than improving the wider region circulation, in particular the Somali Jet and pre-cursor disturbances from the $\mathrm{W}$ Pacific, in realistic representation of monsoon LPS. This was established using a series of regional climate models with different domains and forced with realistic boundary conditions from reanalysis. Improvements to the larger-scale monsoon circulation, in particular to the Somali Jet, with increased horizontal resolution are found, for example, due to improved representation of East African orography (Johnson et al 2016), again using older GA3 configuration global climate simulations. In addition, as some pre-cursor disturbances from the east originate from typhoons or tropical storms in the South China Sea or beyond (Saha et al 1981), it is likely that these are represented more accurately at higher resolution (Roberts et al. 2020), which will again improve conditions for Indian monsoon LPS to form.

The effect of coupling at higher resolution $\left(G L_{90}\right.$ $\left.A T M_{90}[G L]\right)$ seems mostly to amplify these changes, with more LPS and associated rainfall over the central $\mathrm{BoB}$ and less to the north, which is associated with a southwards shift of the monsoon trough to a more realistic location away from the Himalayan foothills. This change in LPS rainfall again helps explain some of the changes seen in the mean seasonal rainfall due to coupling. In fact, locally over the BoB the changes in LPS rainfall account for (almost) all of the changes in the mean seasonal rainfall, as seen in Fig. 5 (note that values can exceed $100 \%$ due to compounding changes in mean rainfall from sources other than LPS). However, the main conclusion is that the effect of increasing resolution from $200 \mathrm{~km}$ to $90 \mathrm{~km}$ is far greater than that of air-sea coupling on Indian monsoon LPS.

With regards to changes in the effects of coupling as horizontal resolution is increased, these are much smaller than the effects of increasing resolution on its own. Therefore, the differences in effects of coupling at different resolutions are more than likely largely the result of the change in atmospheric monsoon base state between the $200 \mathrm{~km}$ and $90 \mathrm{~km}$ resolution simulations.

A comparison of the effects of coupling in individual basins at 90km (N216) horizontal resolution is shown in Figure 14. In general the number of LPS is substantially increased in all 90km (N216) experiments shown in Figure 14 compared to their $200 \mathrm{~km}$ (N96) equivalents from Fig. 6. This further highlights that increasing the horizontal resolution from $200 \mathrm{~km}$ (N96) to $90 \mathrm{~km}$ (N216) dominates over the effects of air-sea coupling.

The positive effects from resolution and coupling combined, however, are still not quite as substantial as the improvements seen when the large-scale monsoon flow into South Asia is corrected, including the poten- tial effects of precursor disturbances entering the monsoon region from the Western Pacific, in regional climate model atmosphere-only experiments (Levine and Martin, 2018). This suggests the biases in the atmospheric mean state and variability still inhibit the simulation of monsoon LPS.

\subsubsection{Changes to wider area seasonal mean circulation}

Seasonal means for Jun-Sept of air temperature at $850 \mathrm{hPa} 806$ and relative humidity at $500 \mathrm{hPa}$ are shown in Figure ${ }_{807}$ 9. Sufficiently high levels of mid-tropospheric humidity are considered to be an important factor in the genesis of monsoon LPS (e.g. Sikka 1977). Also, while there are no large differences in SST between $A T M_{200}[G L] /$ $G L_{200}$ and $A T M_{90}[G L] / G L_{90}$ (see Fig. 2), differences in low-level air temperature may be an important factor in the formation and maintenance of the monsoon LPS.

In general the MetUM simulations are all too dry over most of India and its surrounding seas, with a seemingly large influence of dry and hot air from the continental area to the north west and the Arabian peninsula (see $850 \mathrm{hPa}$ air temperature field), with a particular lack of moisture availability over Indian land. There is improvement in available moisture and with higher resolution over the band covering the Arabian Sea, India and the Bay of Bengal, although there is still a remaining dry bias particularly over Indian land. The low-level air temperature anomalies are improved over the monsoon trough area at higher resolution. However, the persistent lack of available moisture over the land part of the monsoon trough would still act to inhibit systems from propagating westwards over India within the monsoon trough.

Note that in this case the free-running (atmosphere) climate model shows the opposite picture to that found in initialised NWP MetUM simulations by Hunt and Turner (2017), who find an overestimation of mid-level moisture availability in the monsoon trough and improvements as horizontal resolution is increased, indicating that outside/remote influences likely play a role in the simulations used in this study rather than simply being a local convection parametrisation issue.

The low-level circulation and precipitation are shown in Figure 10. Improvements in monsoon rainfall (and LPS rainfall) over India are also associated with an improvement to the excessive equatorial Indian Ocean convection at higher resolution. There are also clear increases in rainfall near bands of sharp (coastal) orography, such as the Western Ghats, Himalayas, and along the Myanmar coast, which are likely a direct result of the increase in resolution, that will contribute to
805 

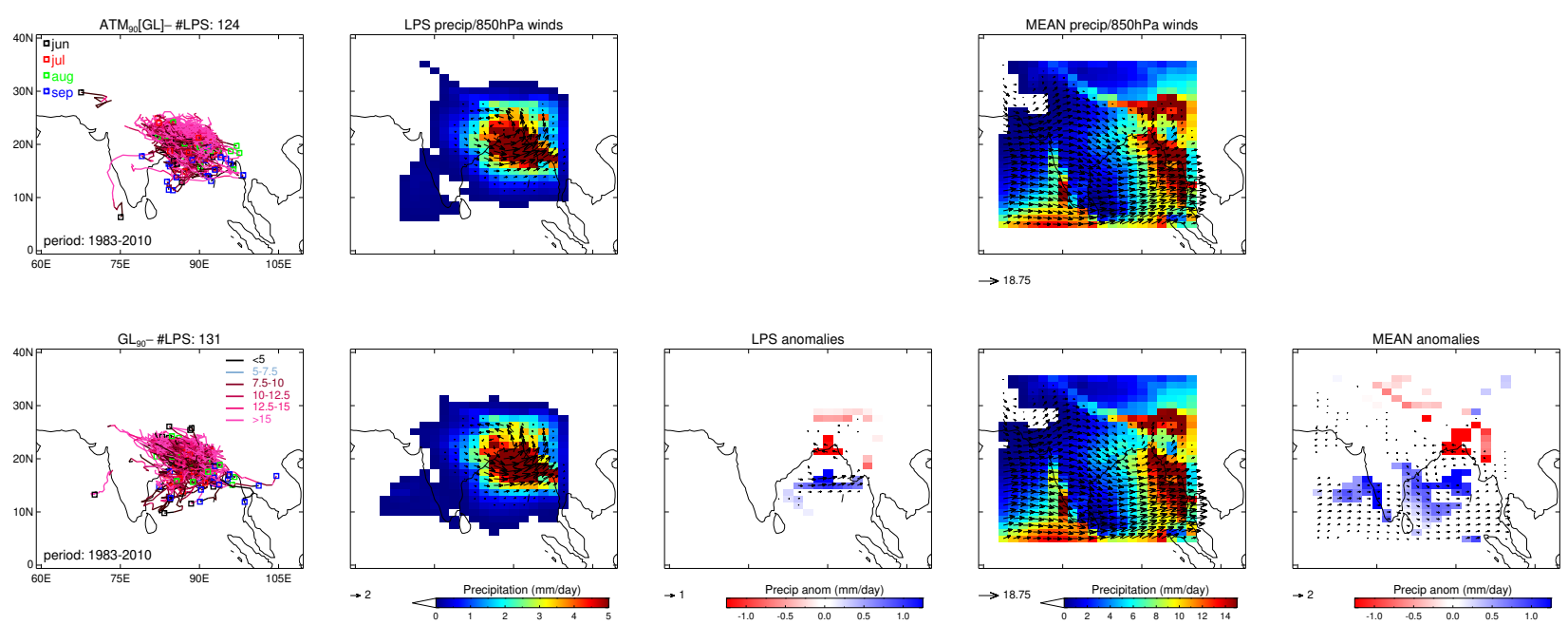

Fig. 8 Monsoon LPS diagnosed in 90km (N216) experiments for 1983-2010 period (only up to 2007 for reanalysis/observations). Top row shows the $A T M_{90}[G L]$ experiment, bottom row shows the $G L_{90}$ experiment, with differences displayed as $\left[G L_{90}-A T M_{90}[G L]\right]$. The layout of the plots is as described in Fig. 4.

improved conditions over the Indian region. Furthermore, correcting the inflow conditions into the Indian monsoon zone has been shown to substantially improve monsoon rainfall over India and also monsoon LPS (Levine and Martin 2018), therefore the dampening of equatorial convection may play a role in the improvements to conditions over the Indian region, including the previously discussed changes to moisture availability.

Upper level circulation fields and precipitation are shown in Figure 11. In addition to improvements to convection and upper-level divergence over the equatorial Indian Ocean there are similar improvements to excessive convection over the equatorial Atlantic Ocean with higher resolution. This could contribute to increases in Indian monsoon rainfall (Yadav 2017) and possibly provide favourable conditions for monsoon LPS, although any definite impacts through this route require further investigation. There are also more complex changes across the Pacific, whose impact on the Indian monsoon is unclear and could be investigated.

The effects of air-sea coupling at higher resolution on the upper-level circulation and precipitation are shown in Figure 12. This shows the largest changes in convection due to global coupling $\left(G L_{90}-A T M_{90}\right)$ over the Indian and Pacific Ocean sectors, while changes over the equatorial Atlantic Ocean are relatively small. There are, however, some changes in the westerly jet across the North Atlantic which may feed into the cyclonic change in upper-level circulation to the north-west of India. If and precisely how this influences monsoon LPS also requires further investigation.
3.4.3 LPS intensity distribution, track and genesis density

Figure 13 shows further statistics for the globally cou- 883 pled GOML2 experiments compared to their atmosphere- ${ }_{884}$ only equivalents. This shows that, once the role of resolution has been eliminated, ERA5 has more occurrences in the moderate intensities compared to all the model simulations, while the model simulations have somewhat more occurrences at higher intensity. This is particularly obvious when looking at the normalised frequency distributions. As well as more low- and moderate strength systems, this also reflects longer-lived strong systems in ERA5, while the systems in the model simulations initially have realistic intensity but are terminated too quickly, with many systems not travelling westwards across India in the monsoon trough.

The result for the $90 \mathrm{~km}$ (N216) simulation is somewhat similar to analysis by Hunt and Turner (2017, Fig. 12a; note that their 200km (N96) to 90km (N216) jump is more dramatic) of MetUM initialised NWP simulations at different resolutions, although the analysis is slightly different in a number of factors. Firstly, Hunt and Turner (2017) use relative vorticity averaged over a cuboid of $400 \mathrm{~km}$ surrounding the origin rather than the value at the centre of the tracked system at the $850 \mathrm{hPa}$ level as used here. Furthermore, here: the results have been filtered down to T42 resolution; LPS that are weaker than standard definitions for monsoon depressions are included in this study; here we use values at the $850 \mathrm{hPa}$ single level instead of an average over $925-750 \mathrm{hPa}$; and perhaps most significantly, the 
simulations analysed here are free-running (in terms of atmosphere) climate simulations instead of initialised NWP simulations.

The track density and genesis show far more limited distributions of LPS in all model simulations compared to ERA5, with systems concentrated far too much over the northern Bay of Bengal. They appear to form in the correct location in the model simulations, but terminate too quickly after making landfall and therefore not enough systems traverse India westwards in the monsoon trough. This results in too little contribution to rainfall over Indian land.

\subsubsection{Impact of air-sea coupling in individual basins at higher resolution}

Analysing the impact of the effects of air-sea coupling in different areas at the higher resolution, the comparison is made using $G L_{90}$ as the reference simulation. In this way we examine the contribution to the overall effect of global coupling from the following four areas:

1. Coupling INSIDE Indian Ocean only: $G L_{90}$ $A O \_P O_{90}$ (Fig. 14, second row),

2. Coupling OUTSIDE Indian Ocean: $G L_{90}-I O_{90}$ (Fig. 14, third row),

3. Coupling OUTSIDE Pacific Ocean: $G L_{90}-P O_{90}$ (Fig. 14, fourth row),

4. Coupling OUTSIDE Indian and Pacific Oceans: $G L_{90}$ - $I O_{-} P O_{90}$ (Fig. 14, fifth row).

The inclusion of air-sea coupling inside the Indian Ocean $\left(G L_{90}\right.$ - $\left.A_{-} P O_{90}\right)$ shows a neutral impact on LPS numbers, unlike in the equivalent $200 \mathrm{~km}$ (N96) simulations. There is though a similar, but smaller, positive impact on monsoon LPS rainfall over the $\mathrm{BoB}$ as found in the N96 simulations. The differences between the impacts at the two resolutions is seen clearer in Figure 15, which shows the $\Delta N 216-\Delta N 96(90 \mathrm{~km}$ $200 \mathrm{~km}$ ) double differences. However, at higher resolution there is also a small negative impact on monsoon LPS rainfall over northern India. This perhaps indicates a role for the negative local effect of air-sea coupling on LPS strength over the BoB, subsequently weakening the systems downstream as they move over land. Or this could be associated with a change in circulation over India.

The inclusion of air-sea coupling outside the Indian Ocean $\left(G L_{90}-I O_{90}\right)$ shows a neutral impact both on LPS numbers and on the mean monsoon flow, again unlike the equivalent $200 \mathrm{~km}$ (N96) simulation impact, while there is a small positive impact on LPS rainfall over the BoB. The impact on monsoon LPS rainfall is similar to effects of coupling inside the Indian Ocean
$\left(G L_{90}-A O \_P O_{90}\right)$, suggesting again that the effects ${ }_{962}$ of coupling inside and outside the Indian Ocean have a ${ }_{963}$ similar impact on monsoon LPS. However, this impact is smaller than at $200 \mathrm{~km}$ (N96) resolution.

Of the other areas shown, there is a much clearer positive effect compared to $200 \mathrm{~km}$ (N96) on monsoon LPS rainfall, and consistent effects on the seasonal mean flow and rainfall, from the coupling outside the Indian and Pacific Ocean $\left(G L_{90}-I O \_P O_{90}\right)$, suggesting the Atlantic Ocean coupling has more influence at higher resolution. There is no obvious direct link between Atlantic Ocean coupled processes and monsoon LPS, though indirect links may include downstream effects of the Atlantic storm-track on the upper-level westerly flow over the Tibetan Plateau or changes in the MJO affecting the active/break cycles of the monsoon. While the larger-scale circulation changes in the $90 \mathrm{~km}$ simulations due to global coupling are relatively small over the Atlantic Ocean (Fig. 12), there are some changes to the westerly jet across the North Atlantic which could merit further investigation.

The differences in the effects of coupling at the two different resolutions (Fig. 15) are relatively small for both coupling outside the Indian Ocean and coupling outside the Pacific Ocean, although highlight the greater reduction of mean JJAS Himalayan rainfall at higher resolution, which is part of the southwards shift of mean JJAS rainfall from the Himalayas seen at both resolutions. The last row of Fig. 15 highlights the increased LPS and mean rainfall at higher resolution with coupling outside the Indian and Pacific Ocean.

\section{Discussion and Conclusions}

The effects of air-sea coupling and horizontal resolution on the climate model simulation of monsoon LPS, which are important contributors to (extreme) Indian monsoon rainfall (Sikka 1977; Krishnamurthy and Ajayamor han 2010; Praveen et al. 2015; Hunt et al. 2016), are 998 examined in order to understand the poor representation of LPS in current global climate models (Ashok et al. 2000; Sabre et al. 2000; Stowasser et al. 2009; Praveen et al. 2015, Levine and Martin 2018). While increasing horizontal resolution may be beneficial for capturing more detail, understanding the (combined) effects of air-sea coupling and horizontal resolution using current coupled models is hampered by the presence of widespread tropical SST biases. Therefore, in this study, we use climate simulations from MetUMGOML2. This model couples the MetUM GA6 atmosphere to a mixed-layer ocean, which constrains the SSTs to observations, thereby minimising (but not eliminating) the effects of SST biases that are common in 
many fully coupled atmosphere-ocean models. The robustness of the remaining SST biases between atmosphereonly MetUM-GOML2 simulations at different resolutions is evidence that this experimental approach ensures a consistent ocean mean state between resolutions, so that differences between the simulations can be attributed to differences in resolution only. Furthermore, while the atmospheric monsoon base state may be slightly different from the standard fully coupled and AMIP-style MetUM simulations, the isolated comparison of MetUM-GOML2 mixed-layer ocean coupled simulations and their equivalent atmosphere-only simulations (forced with GOML2 SSTs) does provide a cleaner decomposition into effects from coupling and from resolution.

Global coupling in the MetUM-GOML2 simulations $(G L-A T M[G L])$, when SST biases are excluded, has a neutral impact on the number of LPS formed, while the associated rainfall is somewhat reduced due to a negative air-sea feedback reducing the strength of atmospheric convection and weakening individual LPS, consistent with dampening effects on extreme tropical rainfall found by Hirons et al. (2018). When compared with a standard MetUM AMIP-type uncoupled run forced with observed SSTs, the MetUM-GOML2 global coupling results in larger numbers of LPS and associated rainfall, suggesting that the SST biases in MetUM-GOML2, though small, do play a role in altering the mean state of the monsoon. While this does not affect the MetUM-GOML2 global coupling ( $G L-$ $A T M[G L])$ comparison, it is relevant in the comparison of regionally coupled simulations, due to differences in SST in the uncoupled regions. This is due to differences in interannual SST variability, for example the uncoupled regions in MetUM-GOML2 coupled simulations are prescribed with climatological monthlyvarying observed SST, and do not contain interannual variability. Furthermore, comparing coupled with uncoupled regions in the MetUM2-GOML2 regionally coupled simulations is affected by the remaining SST biases developing in the coupled regions.

It is found that the regional simulations are particularly sensitive to localised coupling in the Indian and Pacific Oceans, which also has a positive effect on both the number of LPS and associated rainfall when compared with an uncoupled run forced with time-varying observed SSTs. As well as the direct effects of air-sea coupling in the individual oceans, this may also involve the aforementioned differences in SST, and in this case it seems likely that SST biases are at least partly responsible for the positive effects from Indian and Pacific Ocean coupling.
The remote effect of coupling within the Pacific Ocean 1065 may involve impacts on the Indian monsoon through 1066 the Walker circulation, or perhaps a change in the preva- ${ }_{1067}$ lence of westwards-travelling pre-cursor disturbances, 1068 which are thought to originate in the Western Pacific ${ }_{1069}$ (Saha et al. 1981). These mechanisms have been sug- 1070 gested to affect the representation of monsoon LPS in ${ }_{1071}$ regional climate model simulations (Levine and Martin, ${ }_{1072}$ 2018). At higher resolution there is also an increased 1073 effect on LPS from coupling over the Atlantic Ocean. ${ }^{1074}$ Further work is needed to properly establish the nature ${ }_{1075}$ of these remote effects, which could also be the result of ${ }^{1076}$ noise as only a single ensemble member is used in this ${ }_{1077}$ study.

While global air-sea coupling, in the absence of SST 1079 biases, is shown to have a relatively small impact, it 1080 is found that increasing the horizontal resolution from ${ }_{1081}$ N96 ( 200km) to N216 (90km) results in substantially ${ }_{1082}$ larger improvements to both the simulation of Indian 1083 monsoon LPS and the mean state monsoon. Although ${ }_{1084}$ the positive differences here are smaller than the bene- ${ }^{1085}$ fits of eliminating remote biases, such as excessive equa- 1086 torial Indian Ocean convection, observed in regional ${ }_{1087}$ (atmosphere-only) climate model simulations (Levine ${ }_{1088}$ and Martin, 2018), the effects of increasing resolution 1089 on LPS are found to be larger than in previous con- ${ }_{1090}$ figurations of the MetUM (Johnson et al. 2016). While ${ }_{1091}$ there are increased LPS numbers forming over the Bay ${ }_{1092}$ of Bengal and increased LPS rainfall over north-eastern 1093 India in the higher resolution MetUM-GOML2 sim- ${ }_{1094}$ ulations, it is still found that the systems decay too 1095 soon after making landfall over India and many fail to 1096 continue westwards across India within the monsoon 1097 trough. This is consistent with the anomalously hot and 1098 dry conditions that prevail over Indian land and make ${ }_{1099}$ for unfavourable conditions for LPS to be formed or ${ }_{1100}$ maintained.

There are several factors that likely contribute to the improvements in LPS with increased horizontal resolution, including improved resolving of the structure of the LPS. This effect was seen using initialised NWP simulations of monsoon depressions using the same GA6 MetUM configuration by Hunt and Turner (2017), who found the greatest improvements when moving from N96 (denoted in this paper as 200km) to N216 (denoted in this paper as $90 \mathrm{~km}$ ), with little improvement beyond that. Improvements to the larger-scale circulation at higher resolution are also likely important, with Levine and Martin (2018) showing that improving the wider region circulation can have huge benefits to the representation of LPS. As discussed in previous sections, this probably relates to various factors, including dampening of excessive convection over the equatorial Indian 8

69

0

1
2 73 7 70 1077 
Ocean and changes to representation of orography, the latter of which is evident in rainfall changes near bands of sharp (coastal) mountains, and will contribute to improved conditions over the Indian region. Furthermore, there are possible improvements to pre-cursor disturbances from the W Pacific (Levine and Martin, 2018) that are sometimes linked to W Pacific typhoons or tropical storms making landfall (Saha et al 1981). This latter process may play a more prominent role at higher resolution due to improvements to tropical cyclone frequency and structure (Roberts et al. 2020). The new dynamical core ENDGAME included in the MetUM GA6 configuration used in this study enhances tropical variability, including tropical cyclone activity (Walters et al. 2017), and may play a role in the larger changes seen to the monsoon circulation with increased horizontal resolution compared to previous configurations (Johnson et al. 2016).

It is important to note that the methodology used in this study has some limitations, some of which are described in more detail in Hirons et al. (2015) and Peatman and Klingaman (2018): 1) The experiments are relatively short at approximately 30 years. While other studies using this GOML2 methodology (e.g. Peatman and Klingaman (2018)) have used simulations of similar length and found robust results for changes in seasonal mean and intraseaonal precipitation, longer simulations may confirm the findings presented here. 2) While the experiments using the MetUM-GOML2 framework allow a relatively pure comparison of effects of air-sea coupling and resolution, the atmospheric base state is a little different to the standard MetUM AMIP-style simulations, mainly due to remaining cold SST biases (which are still relatively small compared to the fully coupled MetUM), the effects of which require further investigation. 3) In terms of the coupling, the lack of ocean dynamics in the MetUM-GOML2 model means there is no representation of ENSO or IOD variability in the ocean (Hirons et al. 2015). This may be important if there are non-linear effects of ENSO and IOD variability on the number of LPS and their associated rainfall. 4) The uncoupled regions of the regionally coupled simulation are forced with climatological monthly-varying observed SST, which introduces differences in interannual SST variability compared to the globally coupled simulation and the atmosphere-only (AMIP-type) simulation forced with time-varying observed SST. Furthermore, the uncoupled regions do not include any SST biases or interannual variability present in those regions in the atmosphere-only simulation forced with SSTs from the globally coupled simulation. 5) The current study has only tested two horizontal resolutions. 6) The MetUM atmosphere model used has an inherent strong mean dry bias in Indian monsoon rainfall (part of which involves the lack of LPS and associated rainfall, which is also associated with the limited westwards progression over Indian land of these systems).

It is possible that all these factors may influence the results. For example, the positive effects from resolution and coupling combined are still not quite as substantial as the improvements seen when the large-scale monsoon flow into South Asia is corrected (Levine and Martin, 2018), which suggests that the inherent MetUM biases in the atmospheric mean state and variability still inhibit the simulation of monsoon LPS. Using other models that have different mean biases and/or moving to higher horizontal resolutions than used here $(<90 \mathrm{~km})$ may show different sensitivities, although it is worth noting that Hunt and Turner (2017) found little improvements in MetUM NWP case studies of monsoon depressions when resolution was increased beyond 63$39 \mathrm{~km}$. The limitations discussed here require further attention in subsequent investigations.

Acknowledgements This work and its contributors (Richard 1191 Levine and Gill Martin) was supported through the Weather ${ }_{1192}$ and Climate Science for Service Partnership (WCSSP) In- ${ }_{1193}$ dia, a collaborative initiative between the Met Office, sup- ${ }_{1194}$ ported by the UK Government's Newton Fund, and the In- 1195 dian Ministry of Earth Sciences (MoES). Nicholas Klingaman 1196 was supported by an Independent Research Fellowship from ${ }_{1197}$ the Natural Environment Research Council (NE/L010976/1) ${ }_{1198}$ and by the NERC/Global Challenges Research Fund pro- 1199 gramme Atmospheric hazards in developing countries: risk 1200 assessment and early warnings (ACREW). Simon Peatman 1201 was supported by the NERC Bay of Bengal Boundary Layer 1202 Experiment project of the (NE/L013800/1). ERA5 figures 1203 in this paper have been generated using Copernicus Climate ${ }_{1204}$ Change Service Information 2020. The authors would like 1205 to thank the two anonymous reviewers for suggestions that ${ }_{1206}$ helped improve the manuscript.

\section{References}

1. Adler RF, Huffman GJ, Chang A, Ferraro R, Xie PP Janowiak J, Rudolf B, Schneider U, Curtis S, Bolvin D, Gruber A, Susskind J, Arkin P, Nelkin E (2003). The version-2 global precipitation climatology project (GPCP) monthly precipitation analysis (1979-present). J Clim 4:1147-1167

2. Ashok K, Soman MK, Satyan V (2000). Simulation of monsoon disturbances in a GCM. Pure Appl Geophys 157:1509-1539. 2000

3. Bollasina M and Nigam S (2009). Indian Ocean SST, evaporation, and precipitation during the South Asian summer monsoon in IPCC-AR4 coupled simulations. Clim Dyn 33: 1017. https://doi.org/10.1007/s00382-008-0477-4

4. Bollasina MA, Ming Y (2013). The general circulation model precipitation bias over the southwestern equatorial Indian Ocean and its implications for simulating the South Asian monsoon. Clim Dyn 40: 823-838. https://doi.org/10.1007/s00382-012-1347-7 
5. Copernicus Climate Change Service (C3S) (2017): ERA5: Fifth generation of ECMWF atmospheric reanalyses of the global climate. Copernicus Climate Change Service Climate Data Store (CDS), 2020. https://cds.climate.copernicus.eu/cdsapp\#!/home

6. DeMott CA, Stan C, Randall DA, Branson MD (2014). Intraseasonal variability in coupled GCMs: The roles of ocean feedbacks and model physics. J Clim 27: 4970-4995. https://doi.org/10.1175/JCLI-D-13-00760.1

7. DeMott CA, Klingaman NP, Woolnough SJ (2015). Atmosphere-Ocean Coupled Processes in the MaddenJulian Oscillation. Rev Geophys 53: 1099-1154. https://doi.org/10.1002/2014RG000478

8. Fu X and Wang B (2004). Differences of boreal summer intraseasonal oscillations simulated in an atmosphereocean coupled model and an atmosphere-only model. J Clim 17: 1263-1271. https://doi.org/10.1175/15200442(2004)017<1263:DOBSIO > 2.0.CO;2

9. Gao Y, Klingaman NP, DeMott CA, Hsu P-C (2019). Diagnosing ocean feedbacks to the BSISO: SSTmodulated surface fluxes and the moist static energy budget. J Geophys Res Atmos 124: 146-170. https://doi.org/10.1029/2018JD029303

10. Gates WL et al. (1998). An Overview of the Results of the Atmospheric Model Intercomparison Project (AMIP I ). Bull Amer Meteor Soc 73: 1962-1970.

11. Halkides DJ, Waliser DE, Lee T, Menemenlis D, Guan B (2015). Quantifying the processes controlling intraseasonal mixed-layer temperature variability in the tropical Indian Ocean. J Geophys Res Oceans 120: 692- 715. https://doi.org/10.1002/2014JC010139

12. Hirons LC, Klingaman NP, Woolnough SJ (2015), MetUM-GOML1: a near-globally coupled atmosphere-ocean-mixed-layer model, Geosci Model Dev 8: 363-379, 2015. https://doi.org/10.5194/gmd-8-363-2015

13. Hirons LC, Klingaman NP, Woolnough SJ (2018). The impact of air-sea interactions on the representation of tropical precipitation extremes. J Adv Model Earth Sy 10: 550-559. https://doi.org/10.1002/2017MS001252

14. Hodges KI (1994). A general method for tracking analysis and its application to meteorological data. Mon Weather Rev 122:2573-2586

15. Hsu W-C, Patricola M, Chang P (2019). The impact of climate model sea surface temperature biases on tropical cyclone simulations. Clim Dyn 53(1-2): 173-192. https://doi.org/10.1007/s00382-018-4577-5

16. Hunt KMR, Turner AG, Inness PM, Parker DE, Levine RC (2016). On the structure and dynamics of Indian monsoon depressions. Mon Weather Rev 144(9): 3391-3416. https://doi.org/10.1175/MWR-D-15-0138.1

17. Hunt KMR and Turner AG (2017). The effect of horizontal resolution on Indian monsoon depressions in the Met Office NWP model. Q J R Meteorol Soc. https://doi.org/10.1002/qj.3030

18. Johnson SJ, Levine RC, Turner AG, Martin GM, Woolnough SJ, Schiemann R, Mizielinski MS, Roberts MJ, Vidale PL, Demory M-E, Strachan J (2016). The resolution sensitivity of the South Asian Monsoon and Indo-Pacific in a global 0.35 degree AGCM. Clim Dynam. 46: 807. https://doi.org/10.1007/s00382-015-2614-1

19. Karmacharya J, Levine RC, Jones R, Moufouma-Okia W, New M (2015). Sensitivity of systematic biases in South Asian summer monsoon simulations to regional climate model domain size and implications for downscaled regional process studies. Clim Dynam. 45(1-2):213-231. https://doi.org/10.1007/s00382-015-2565-6
20. Karmacharya J, New M, Jones R, Levine R (2016). ${ }_{1293}$ Added value of a high resolution regional climate 1294 model in simulation of intraseasonal variability of 1295 the South Asian summer monsoon. Int J Climatol. ${ }_{1296}$ https://doi.org/10.1002/joc.4767

21. Klingaman NP and Woolnough SJ (2014). The role of ${ }_{1298}$ air-sea coupling in the simulation of the Madden-Julian os- 1299 cillation in the Hadley Centre model. Q J Roy Meteor Soc 1300 140:2272-2286. https://doi.org/10.1002/qj.2295

22. Krishnamurthy V and Shukla J (2007). Intraseasonal and seasonally persisting patterns of Indian monsoon rainfall. J Clim 20:3-20. https://doi.org/10.1175/JCLI3981.1

23. Krishnamurty V and Ajayamohan RS (2010). Composite Structure of Monsoon Low Pressure Systems and Its Relation to Indian Rainfall. J Clim. 23-4285-4305. https://doi.org/10.1175/2010JCLI2953.1

24. Levine RC and Martin GM (2018). On the climate model simulation of Indian monsoon low pressure systems and the effect of remote disturbances and systematic biases. Clim Dynam 50(11-12):4721-4743. https://doi.org/10.1007/s00382-017-3900-x

25. Levine RC, Turner AG, Marathayil D, Martin GM (2013). The role of northern Arabian Sea surface temperature biases in CMIP5 model simulations and future projections of Indian summer monsoon rainfall. Clim Dyn 41: 155-172. https://doi.org/10.1007/s00382-012-1656-x

26. Levine RC, Turner AG (2012). Dependence of Indian monsoon rainfall on moisture fluxes across the AS and the impact of coupled model sea surface temperature biases. Clim Dynam 38(11-12):2167-2190. https://doi.org/10.1007/s00382-011-1096-z

27. Peatman SC and Klingaman NP (2018). The Indian summer monsoon in MetUM-GOML2.0: effects of air-sea coupling and resolution. Geosci Model Dev 11:4693-4709. https://doi.org/10.5194/gmd-11-4693-2018

28. Praveen V, Sandeep S, Ajayamohan RS (2015). On the Relationship between Mean Monsoon Precipitation and Low Pressure Systems in Climate Model Simulations. J Clim 28:5305-5324. https://doi.org/10.1175/JCLI-D-1400415.1

29. Prodhomme C, Terray P, Masson S et al. (2014). Impacts of Indian Ocean SST biases on the Indian Monsoon: as simulated in a global coupled model. Clim Dyn 42: 271-290. https://doi.org/10.1007/s00382-013-1671-6

30. Reynolds RW, Smith TM, Liu C, Chelton DB, Casey KS, Schlax MG (2007) Daily high-resolution-blended analyses for sea surface temperature. J Clim 20:5473-5496. https://doi.org/10.1175/2007JCLI1824.1

31. Roberts MJ et al. (2020). Impact of Model Resolution on Tropical Cyclone Simulation Using the HighResMIP-PRIMAVERA Multimodel Ensemble. J Clim 33: 2557-2583. https://doi.org/10.1175/JCLI-D-19-0639.1

32. Sabre M, Hodges KI, Laval K, Polcher J, Desalmand F (2000). Simulation of monsoon disturbances in the LMD GCM. Mon Weather Rev 128:3752-3771

33. Saha K, Sanders F, Shukla J (1981). Westward Propagating Predecessors of Monsoon Depressions, Mon Weather Rev. 109:330-343. https://doi.org/10.1175/15200493(1981) $109<0330$ :WPPOMD $>2.0 . \mathrm{CO} ; 2$

34. Shukla RP, Huang B (2016). Interannual variability of the Indian summer monsoon associated with the air-sea feedback in the northern Indian Ocean. Clim Dyn 46: 1977-1990. https://doi.org/10.1007/s00382-015-2687-x

35. Sikka DR (1977). Some aspects of the life history, structure and movement of monsoon depressions. Pure Appl Geophys. 115:1501-1529 
36. Smith DM, Murphy JM (2007). An objective ocean temperature and salinity analysis using covariances from a global climate model. J Geophys Res Ocean 112 (C02022). https://doi.org/10.1029/2005JC003172

37. Stowasser M, Annamalai H, Hafner J (2009). Response of the South Asian summer monsoon to global warming: mean and synoptic systems. J Clim 22:1014-1036. https://doi.org/10.1175/2008JCLI2218.1

38. Subrahmanyam B, Murty VSN, Sharp RJ, O'Brien JJ (2005). Air-sea Coupling During the Tropical Cyclones in the Indian Ocean: A Case Study Using Satellite Observations. Pure appl geophys 162: 1643-1672. https://doi.org/10.1007/s00024-005-2687-6

39. Wainwright CM, Hirons LC, Klingaman NP, Allan RP, Black E, Turner AG (2019) The impact of air-sea coupling and ocean biases on the seasonal cycle of southern West African precipitation. Clim Dyn 53: 7027-7044. https://doi.org/10.1007/s00382-019-04973-0

40. Walters DN et al. (2011). The Met Office Unified Model Global Atmosphere 6.0/6.1 and JULES Global Land 3.0/3.1 configurations. Geosci Model Dev 4: 919-941. https://doi.org/10.5194/gmd-4-919-2011

41. Walters DN et al. (2017). The Met Office Unified Model Global Atmosphere 6.0/6.1 and JULES Global Land 6.0/6.1 configurations. Geosci Model Dev 10(4), 1487-1520. https://doi.org/10.5194/gmd-10-1487-2017

42. Williams KD et al. (2015). The Met Office Global Coupled model 2.0 (GC2) configuration. Geosci Model Dev 8: 1509-1524. https://doi.org/10.5194/gmd-8-1509-2015

43. Wu G, Guan Y, Liu Y, Yan J, Mao J (2012). Air-sea interaction and formation of the Asian summer monsoon onset vortex over the Bay of Bengal. Clim Dyn 38(1-2): 261-279. https://doi.org/10.1007/s00382-010-0978-9

44. Yadav RK (2017). On the relationship between east equatorial Atlantic SST and ISM through Eurasian wave. Clim Dyn 48: 281-295. https://doi.org/10.1007/s00382016-3074-y

45. Yatagai A, Kamiguchi K, Arakawa O, Hamada A, Yasutomi N, Kitoh A (2012). APHRODITE: Constructing a Long-Term Daily Gridded Precipitation Dataset for Asia Based on a Dense Network of Rain Gauges. BAMS. September 2012:1401-1415 


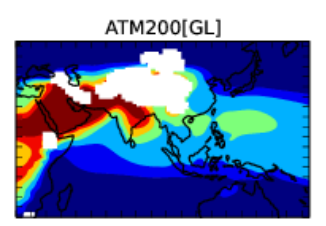
$288 \underset{290 \quad 292}{29} 294 \quad 296 \quad 298$
air_temperature
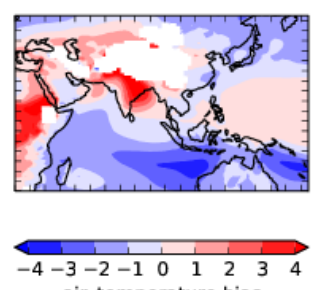

air_temperature bias

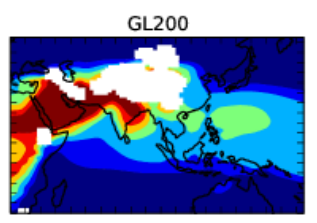
$\begin{array}{llll}288 & 290 \quad 292 & 294 \quad 296 & 298 \\ \text { air_temperature } & \end{array}$
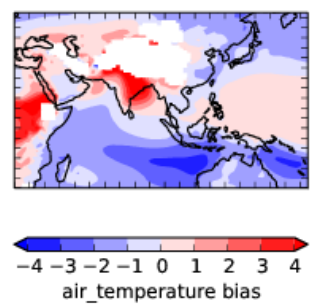

air_temperature bias
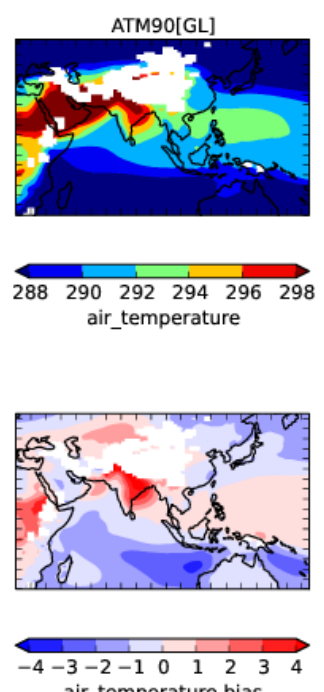

air_temperature bias
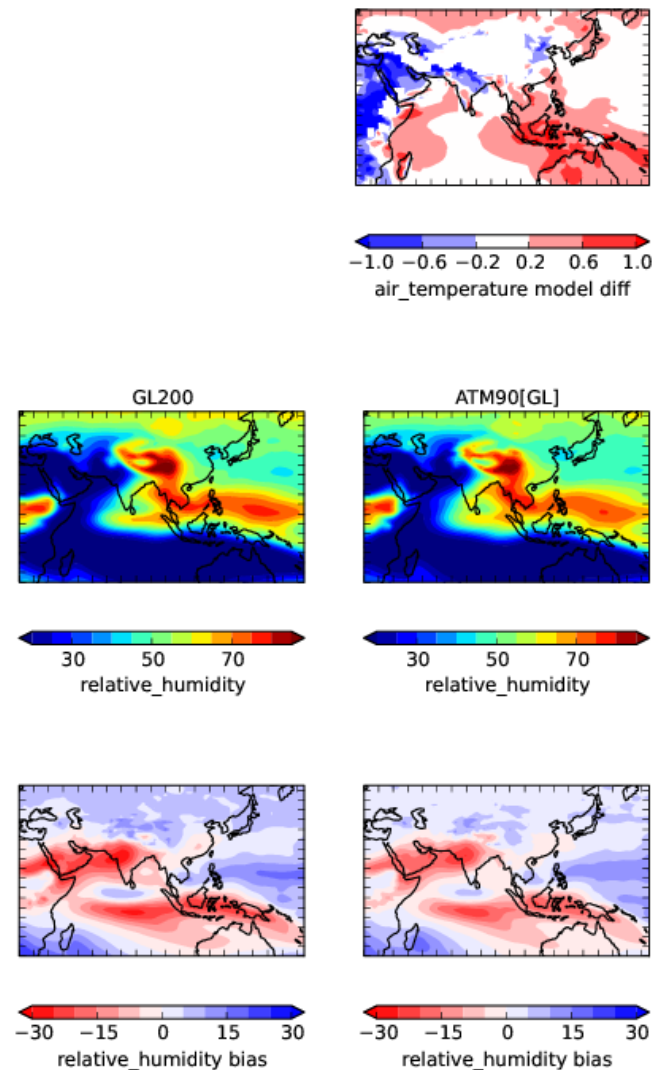

ATM90[GL]
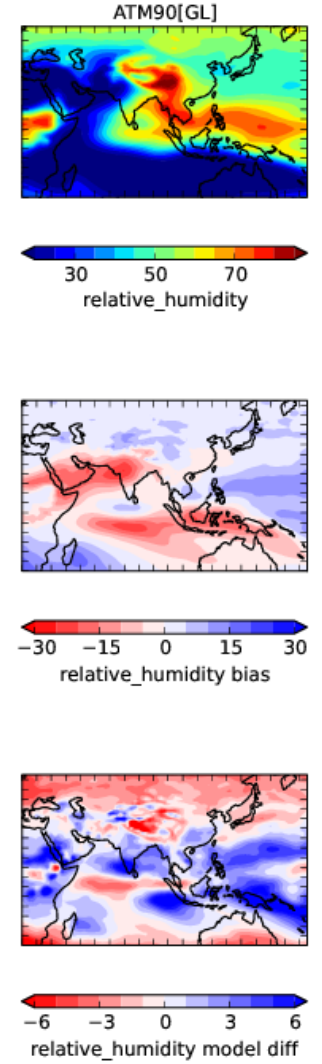
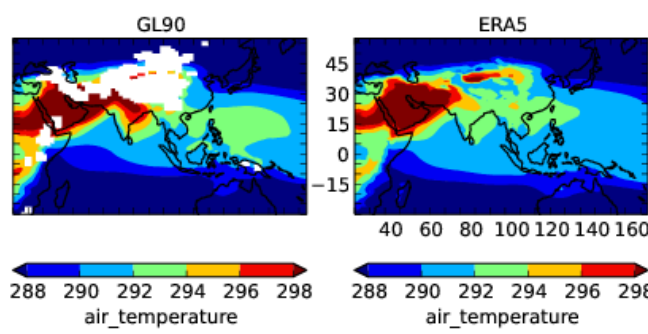

\begin{tabular}{|lllllll}
40 & 60 & 80 & 100 & 120 & 140 & 160 \\
\hline 88 & 290 & 292 & 294 & 296 & 298
\end{tabular} air_temperature
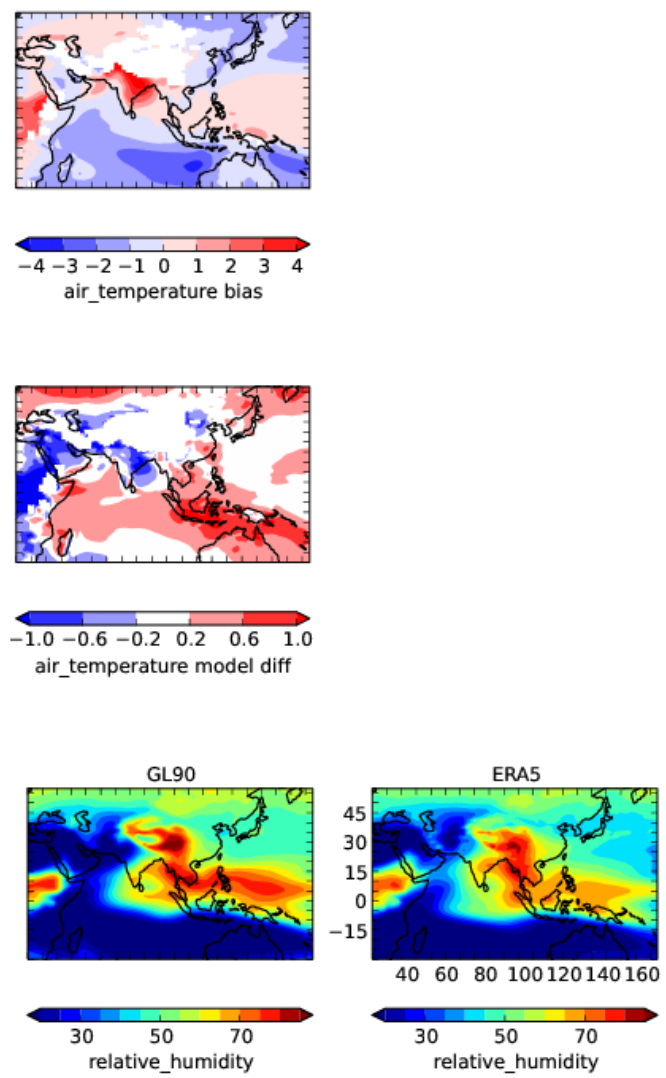

406080100120140160
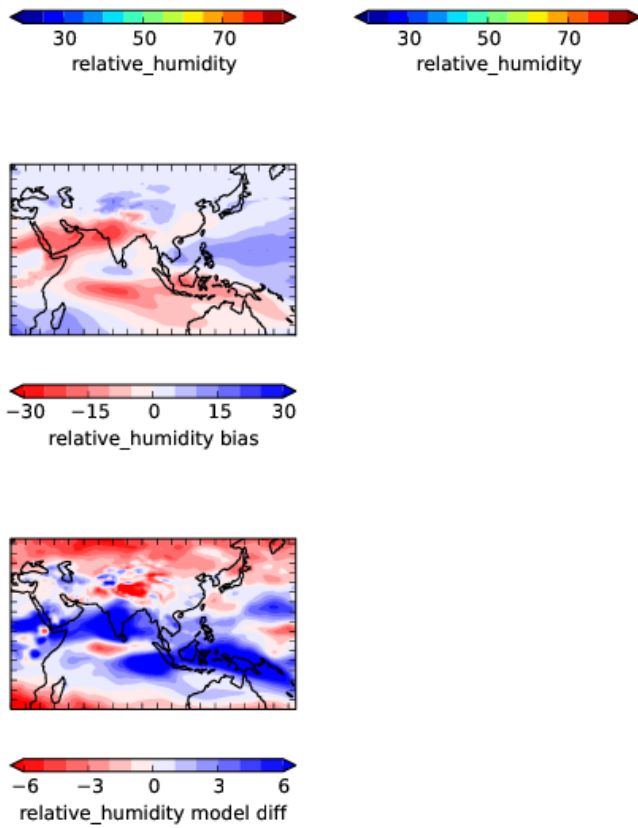

Fig. 9 Row (1) Air temperature (in K, average for Jun-Sept) at 850hPa. Row (2) Differences compared to ERA5. Row (3) $90 \mathrm{~km}$ minus $200 \mathrm{~km}\left(A T M_{90}[G L]-A T M_{200}[G L]\right.$ and $\left.G L_{90}-G L_{200}\right)$ and relative humidity (in \%, average for Jun-Sept) at $500 \mathrm{hPa}$ for Jun-Sept and differences compared to ERA5 in same layout as for air temperature. Seasonal Jun-Sept means for the period 1983-2010. The ERA5 figures have been generated using Copernicus Climate Change Service Information 2020. 


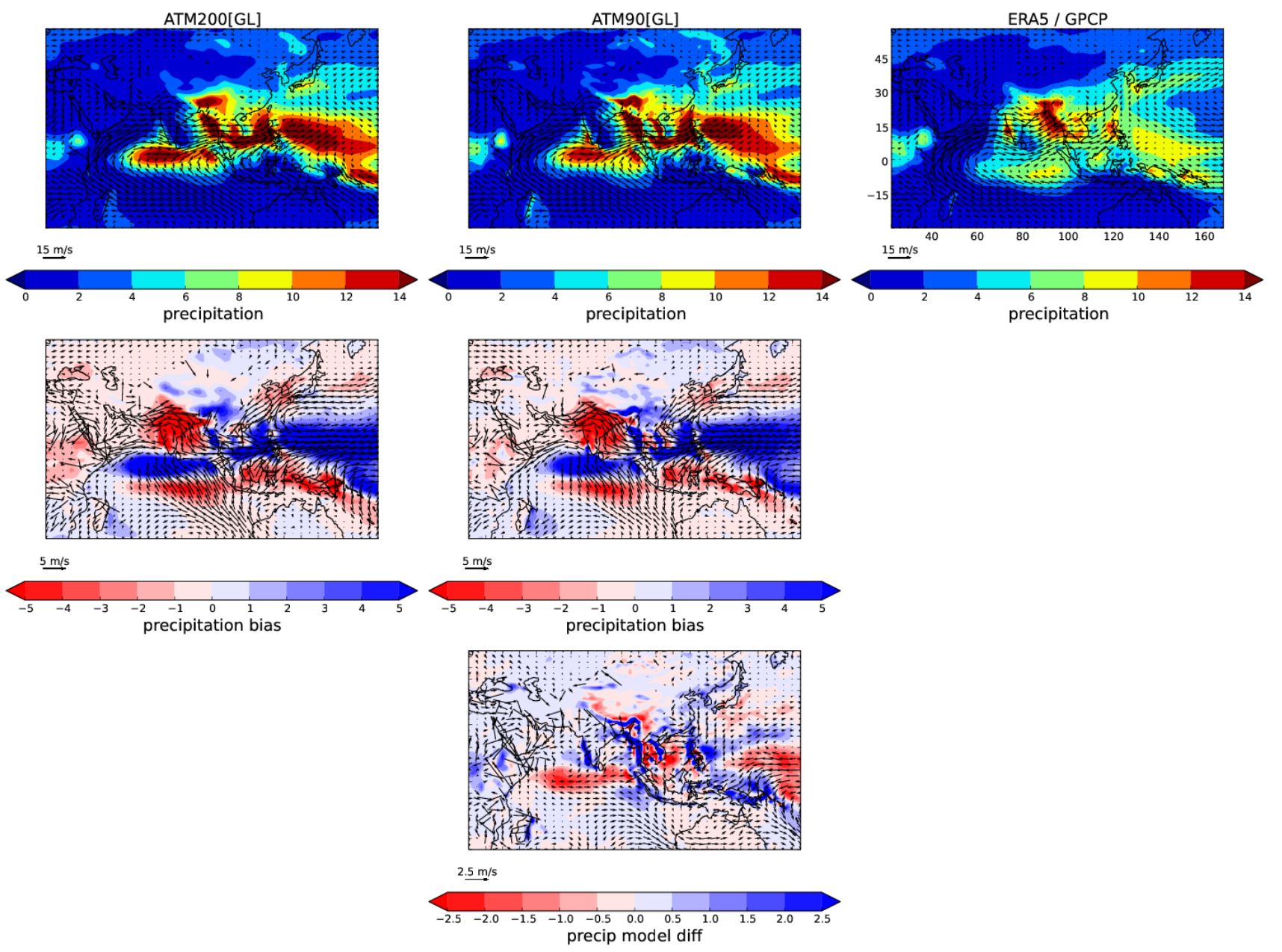

Fig. 10 Row (1) Precipitation (mm/day, coloured contours) and 850hPa winds (m/s, vectors). Row (2) Differences compared to ERA5 and GPCP precipitation. Row (3) $90 \mathrm{~km}$ minus $200 \mathrm{~km}\left(A T M_{90}[G L]-A T M_{200}[G L]\right.$. Seasonal Jun-Sept means for the period 1983-2010. The ERA5 figures have been generated using Copernicus Climate Change Service Information 2020.
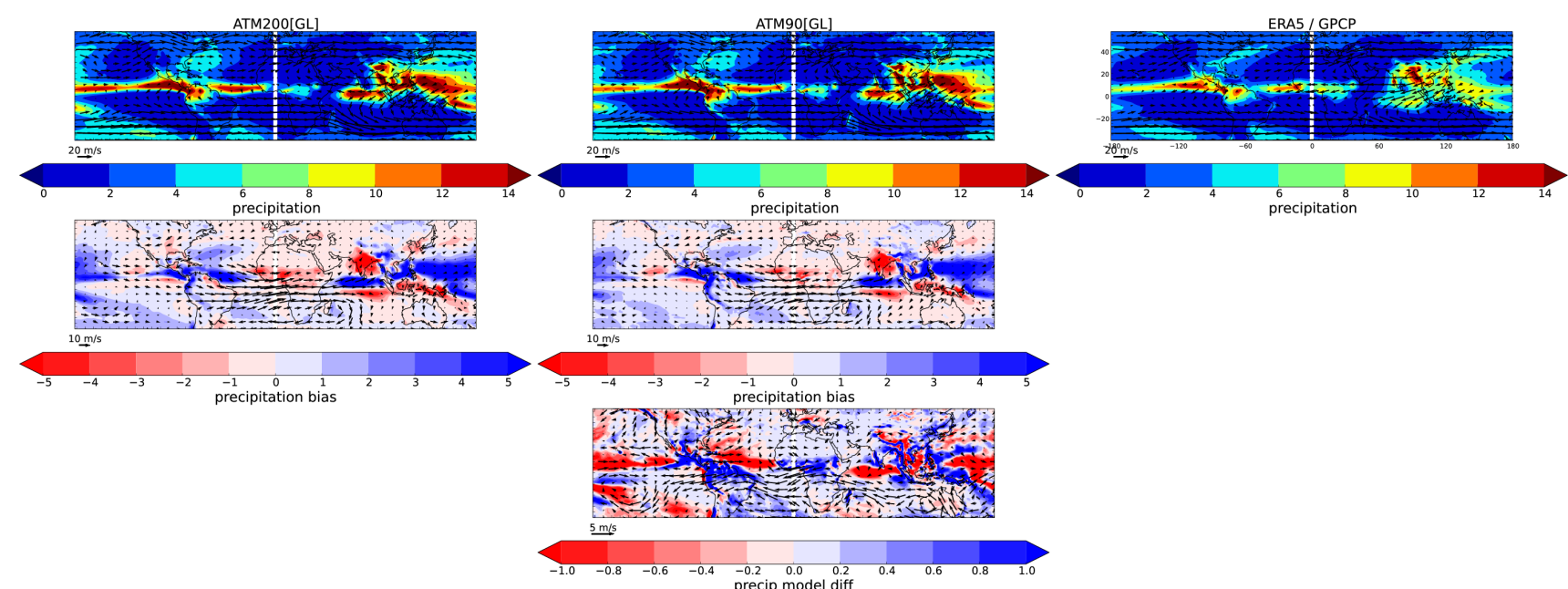

Fig. 11 Row (1) Precipitation (mm/day, coloured contours) and 200hPa winds (m/s, vectors). Row (2) Differences compared to ERA5 and GPCP precipitation. Row (3) $90 \mathrm{~km}$ minus $200 \mathrm{~km}\left(A T M_{90}[G L]-A T M_{200}[G L]\right.$. Seasonal Jun-Sept means for the period 1983-2010. The ERA5 figures have been generated using Copernicus Climate Change Service Information 2020. 


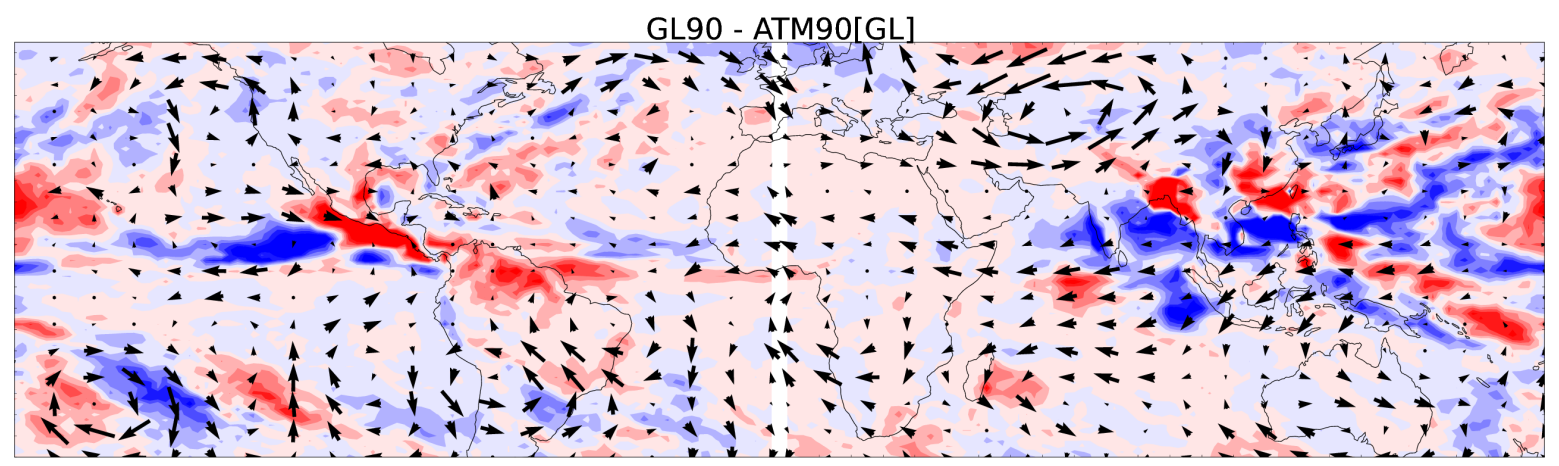

$\stackrel{5 \mathrm{~m} / \mathrm{s}}{\longrightarrow}$

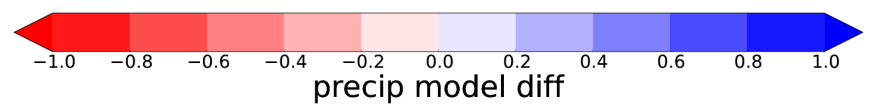

Fig. 12 Differences in precipitation (mm/day, coloured contours) and 200hPa winds (m/s, vectors) for global coupling minus atmosphere-only simulations at $90 \mathrm{~km}\left(G L_{90}[G L]-A T M_{90}[G L]\right)$. Seasonal Jun-Sept mean for the period 1983-2010.
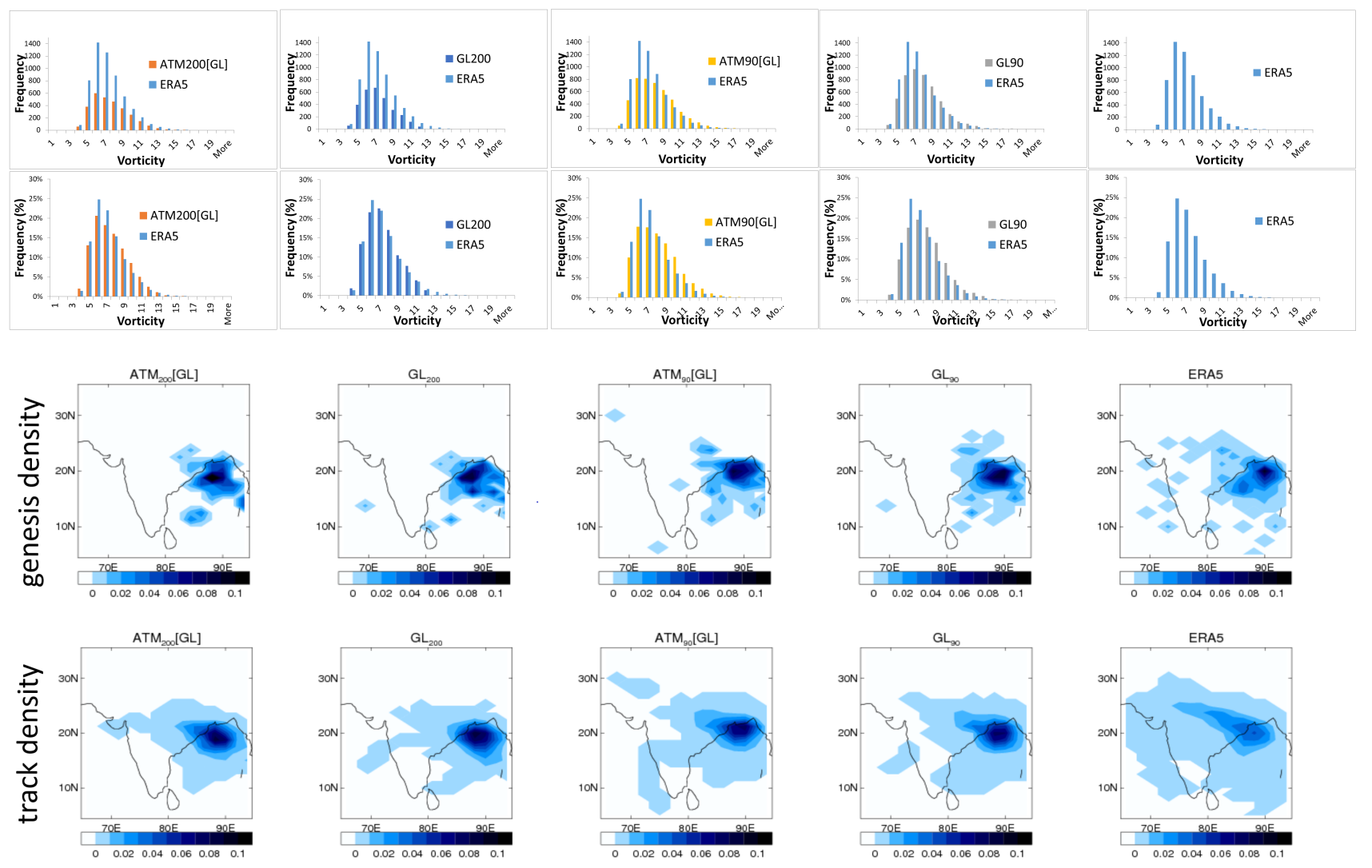

Fig. 13 LPS intensity histograms (as described in Fig. 1). First row is total occurrences, second row is normalised frequency distribution, third row is LPS track genesis (from equation 2), fourth row is LPS track density (from equation 1). The columns show experiments $A T M_{200}[G L], G L_{200}, A T M_{90}[G L], G L_{90}, E R A 5$. The ERA5 figures have been generated using Copernicus Climate Change Service Information 2020. 

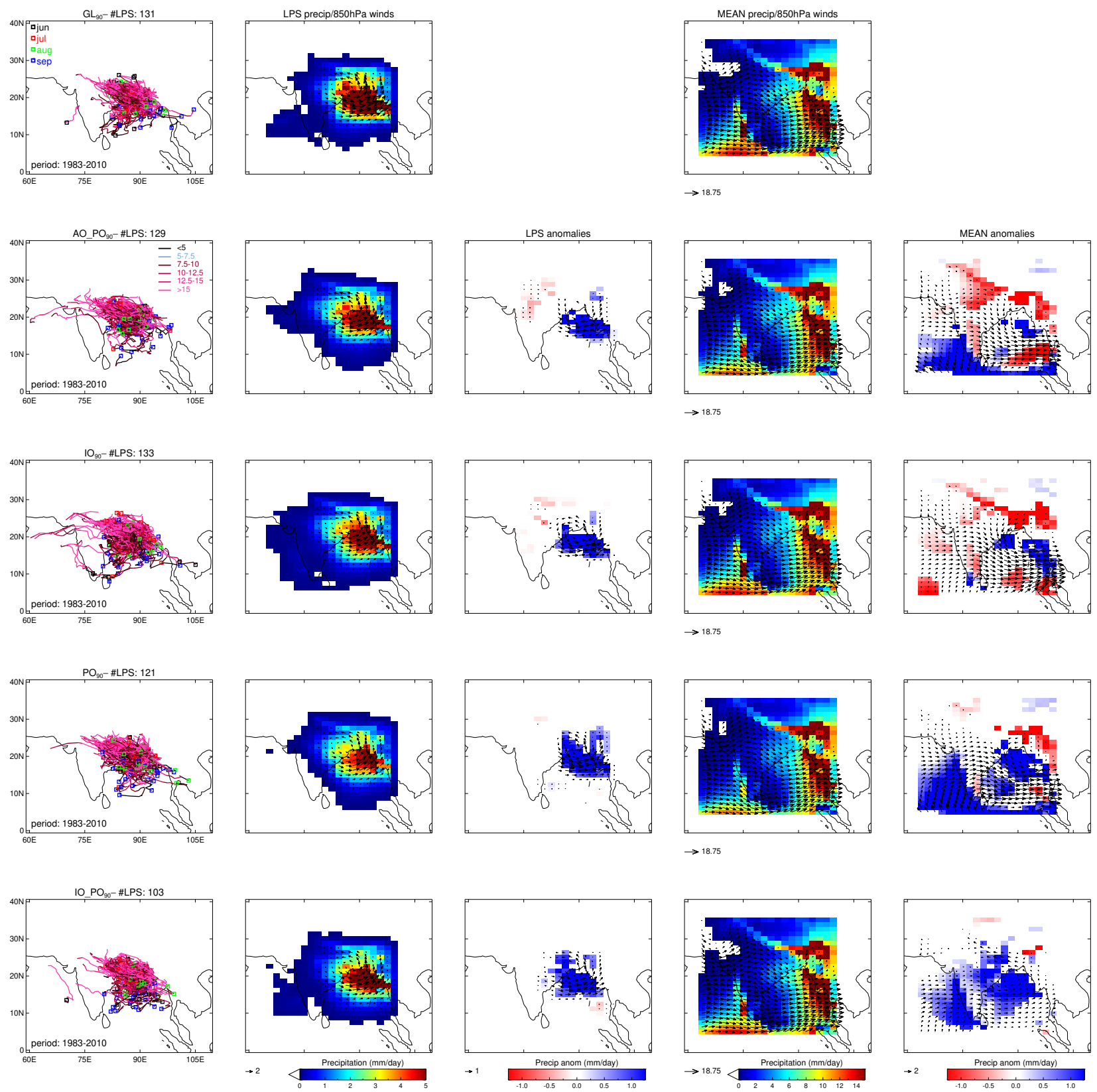

Fig. 14 Coupling sensitivity of 90km (N216) simulations for 1983-2010 period. Top row shows the Global Coupling (obs) experiment, while subsequent rows show the results for regional coupling and differences displayed as $\left[G L_{90}-A O_{-} P O_{90}\right]$ (coupling INSIDE Indian Ocean), $\left[G L_{90}-I O_{90}\right]$ (coupling OUTSIDE Indian Ocean), [GL90 - PO90] (coupling OUTSIDE Pacific Ocean), [GL $\left.L_{90}-I_{-} P_{90}\right]$ (coupling OUTSIDE Indian and Pacific Oceans). The layout of the plots is as described in Fig. 4. 

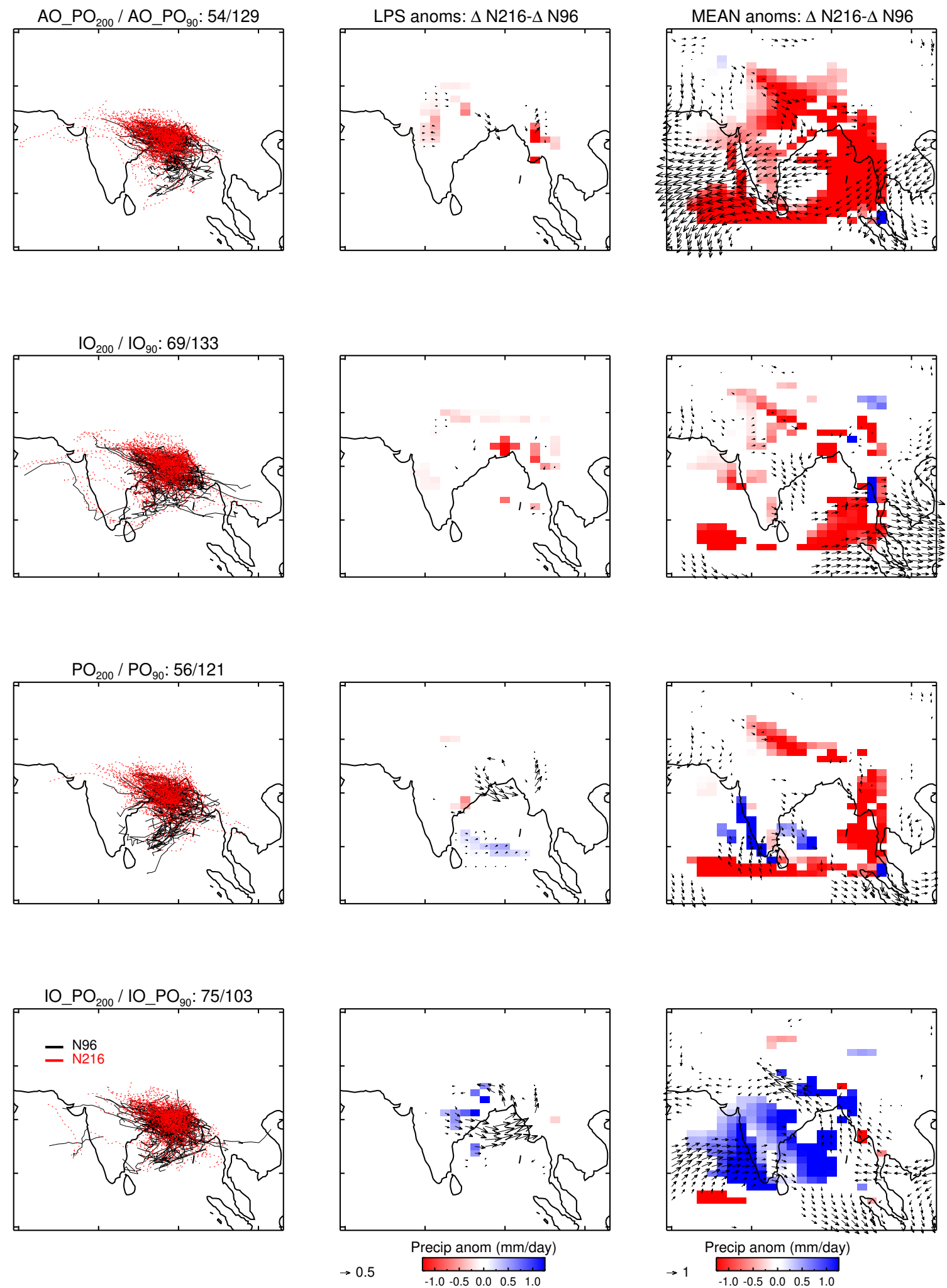

Fig. 15 Comparison of coupling sensitivity for coupling experiments (EXPT) at 90km (N216) versus 200km (N96) simulations for 1983-2010 period in terms of double differences: $\Delta N 216-\Delta N 96=\left(G L_{90}-E X P T_{90}\right)-\left(G L_{200}-E X P T_{200}\right)$. The first panel on left hand-side shows LPS trajectories with the total number of LPS in title for N96 (black) and N216 (red dotted). The second panel from left shows double differences in LPS contribution to Jun-Sept seasonal mean precipitation (mm/day) and $850 \mathrm{hPa}$ winds (m/s, black vectors). The third panel from left shows double differences Jun-Sept seasonal mean precipitation $(\mathrm{mm} /$ day $)$ and $850 \mathrm{hPa}$ wind $(\mathrm{m} / \mathrm{s})$ contributions. All data in panels two and three are plotted on a common 200km (N96; $\left.1.875^{\circ} \times 1.25^{\circ}\right)$ grid. Only significant differences and vectors at $90 \%$ level using a student t-test are shown. Values exceeding the colour scale maxima are capped at the relevant maximum colour value. 